\title{
Ex Ante Skewness and Expected Stock Returns
}

First Draft: March 2007

This Draft: January 11, 2012

\begin{abstract}
We use a sample of option prices to estimate the ex ante higher moments of the underlying individual securities' risk-neutral returns distribution. We find that individual securities' risk neutral volatility, skewness, and kurtosis are strongly related to future returns. Specifically, we find a negative relation between past volatility and subsequent returns in the cross-section. We also find that ex ante more negatively (positively) skewed returns are associated with subsequent higher (lower) returns, while ex ante kurtosis is positively related to subsequent returns. We analyze the extent to which these returns relations represent compensation for risk and find evidence that, even after controlling for differences in co-moments, individual securities' skewness matters.
\end{abstract}




\section{Introduction}

Models implying that investors consider higher moments in returns have a long history in the literature. Researchers such as Rubinstein (1973), Kraus and Litzenberger (1976) and Kraus and Litzenberger (1983) develop models of expected returns which incorporate skewness. In these models, the higher moments which are relevant for individual securities are co-moments with the aggregate market portfolio. Subsequently, empirical work provided evidence that higher moments of the return distribution are important in pricing securities. Consistent with the models' focus on co-moments, the tests in these papers ask whether a security's coskewness or co-kurtosis with the market is priced; historical returns data are typically used to measure these co-moments. For example, Harvey and Siddique (2000) explore both skewness and co-skewness and test whether co-skewness is priced, and Dittmar (2002) tests whether a security's co-skewness and co-kurtosis with the market portfolio might influence investors' expected returns.

Other recent papers have suggested that additional features of individual securities' payoff distribution may be relevant for understanding differences in assets' returns. For example, Ang, Hodrick, Xing, and Zhang (2006) and Ang, Hodrick, Xing, and Zhang (2009) document that firms' idiosyncratic return volatility contains important information about future returns. The work of Barberis and Huang (2008), Brunnermeier, Gollier, and Parker (2007), and the empirical evidence presented in Mitton and Vorkink (2007) and Boyer, Mitton, and Vorkink (2010) imply that the skewness of individual securities may also influence investors' portfolio decisions. Xing, Zhang, and Zhao (2010) find that portfolios formed by sorting individual securities on a measure which is related to idiosyncratic skewness generate cross-sectional differences in returns. Green and Hwang (2009) use the approach of Zhang (2006) and find that IPOs with high expected skewness ('lottery' stocks) experience significantly greater first-day returns, followed by substantially greater negative abnormal returns in the subsequent three to five years.

We therefore have two strands in the existing literature: (1) models and empirical results that emphasize the importance of higher moments as they affect stochastic discount factors, (2) models and empirical evidence that focus on the higher moment characteristics of individual securities. In this second strand of the literature, researchers have proposed both behavioral and rational models. For example, Barberis and Huang (2008) argue that investors with cumulative prospect theory preferences demand securities with highly skewed payoffs, such as IPO stocks. Brunnermeier, Gollier, and Parker (2007) develop a model of optimal (as opposed to rational) beliefs which also predicts that investors will overinvest in the most highly (right) skewed securities, with the consequence that those securities will have 
lower subsequent average returns. They also show that, while there is a rational expectations solution to their model, it represents a knife-edge case. Mitton and Vorkink (2007) introduce a rational model where investors have heterogeneous preferences for skewness and show that idiosyncratic skewness can impact prices. Chabi-Yo, Ghysels, and Renault (2010) also present a model where heterogeneity of beliefs across rational investors can generate a pricing kernel which depends on idiosyncratic moments.

In this paper, we examine the importance of higher moments using a new approach. We exploit the fact that if option and stock prices reflect the same information, then it is possible to use options market data to extract estimates of the higher moments of the securities' (risk-neutral) probability density function. Our method has several advantages. First, option prices are a market-based estimate of investors' expectations. Many authors, including Bates (1991), Rubinstein (1994) and Jackwerth and Rubinstein (1996) have argued that option market prices can capture the information of market participants. Second, the use of option prices eliminates the need of a long time series of returns to estimate the moments of the return distribution; this is especially helpful when trying to forecast the payoff distribution of relatively new firms or during periods where expectations, at least for some firms, may change relatively quickly. Third, options reflect a true ex ante measure of expectations; they do not give us, as Battalio and Schultz (2006) note, the "unfair advantage of hindsight." As Jackwerth and Rubinstein (1996) state, "not only can the nonparametric method reflect the possibly complex logic used by market participants to consider the significance of extreme events, but it also implicitly brings a much larger set of information ... to bear on the formulation of probability distributions."

We begin with a sample of options on individual stocks, and test whether cross-sectional differences in estimates of the higher moments of an individual security's payoff extracted from options are related to subsequent returns. Consistent with the Ang, Hodrick, Xing, and Zhang (2006) and Ang, Hodrick, Xing, and Zhang (2009) findings for physical measures of idiosyncratic volatility, we find a negative relation between risk-neutral volatility and subsequent returns. We also document a significant negative relation between firms' risk-neutral skewness and subsequent returns - that is, more negatively skewed securities have higher subsequent returns. In addition, we find a significant positive relation between firms' riskneutral kurtosis and subsequent returns. These relations persist after controlling for firm characteristics, such as beta, size, and book-to-market ratios, and adjustment for the Fama and French (1993) risk factors.

We examine the extent to which these relations between risk-neutral higher moments and subsequent returns are determined by co-moments with the market portfolio. We measure co-moments using the approaches of Harvey and Siddique (2000) and Bakshi, Kapadia, and 
Madan (2003), and then decompose total moments into co-moments - such as co-skewness and idiosyncratic moments. We find that the relation between idiosyncratic higher moments, particularly idiosyncratic skewness, and subsequent returns persists, even after controlling for differences in covariance, co-skewness and co-kurtosis. ${ }^{1}$

Our results are consistent with models such as Brunnermeier, Gollier, and Parker (2007), and Barberis and Huang (2008), which predict that investors will trade off the benefits of diversification and skewness, holding more concentrated positions in skewed securities, and resulting in a negative relation between idiosyncratic skewness and expected returns. These results are also consistent with the empirical evidence in Mitton and Vorkink (2007), who examine the choices of investors in a sample of discount brokerage accounts and find that investors appear to hold relatively undiversified portfolios and accept lower Sharpe ratios for positively skewed portfolios and securities. These papers focus on physical moments of returns, in contrast to the risk-neutral moments that we examine. Consequently, we analyze the relation between our risk-neutral estimates of skewness and estimates formed from historical returns. We find a positive and statistically significant relation between these estimates; however, we find comparatively little evidence that the relation between risk-neutral moments and subsequent returns in our sample is driven by this relation; that is, after controlling for differences in physical moments, the predictive relation between risk-neutral moments and subsequent returns continues to hold. In contrast, after controlling for differences in risk-neutral moments, we find no clear pattern in returns for portfolios which differ in physical skew.

The remainder of the paper is organized as follows. In section 2 , we detail the method we employ for recovering measures of volatility, skewness, and kurtosis, following Bakshi, Kapadia, and Madan (2003) and we discuss the data (and data filters) used in our analysis. In Section 3 we focus on testing whether estimates of the ex ante higher moments of the payoff distribution obtained from options data are related to the subsequent returns of the underlying security. In Section 4, we analyze the extent to which the relations between option-based ex ante higher moment sorts and subsequent returns are due to investors seeking compensation for higher co-moment risk, rather than idiosyncratic moments. We examine in Section 5 the relation between risk-neutral and physical distributions, and in particular the comparison of portfolio sorts based on skewness under both measures. We conclude in Section 6.

\footnotetext{
${ }^{1}$ In robustness checks, we also explore a stochastic discount factor approach and consider several alternative specifications of the stochastic discount factor, both parametric and non-parametric. We find results similar to those obtained from the decomposition of higher moments. These results are available in a companion document containing supplementary material: see BLANK (2011).
} 


\section{Data and Computing Ex Ante Risk-Neutral Moments}

We wish to examine the relation, if any, between features of the risk-neutral density function and the pricing of stocks. In this section we describe the data and the methods used to compute ex ante estimates of volatility, skewness, and kurtosis.

Our data on option prices are from Optionmetrics (provided through Wharton Research Data Services). We begin with daily option price data for all out-of-the-money calls and puts for all stocks from 1996-2005. Closing prices are constructed as midpoint averages of the closing bid and ask prices.

Data on stock returns are obtained from the Center for Research in Security Prices (again provided through Wharton Research Data Services). We employ daily and monthly returns from 1996-2005 for all individual securities covered by CRSP with common shares outstanding. Risk free rates are the continuously compounded yield computed from the bank discount yields on secondary market three month Treasury Bills taken from the Federal Reserve Report H.15. Finally, we obtain balance sheet data for the computation of book-to-market ratios from Compustat and compute these ratios following the procedure in Davis, Fama, and French (2000).

We begin by calculating higher moments of firms' risk neutral probability distributions. Intuitively, a risk neutral probability distribution is computed so that today's fair (i.e. arbitragefree) price of an asset is equal to the discounted expected value of the future payoffs of the asset, where the discount rate used is simply the riskfree rate. Thus, under the risk neutral measure, all financial assets in the economy have the same expected rate of return, regardless of their risk. In contrast, if we use the actual (or physical) probability distribution of the asset's payoffs and assume that investors are risk-averse, assets which have more risk in their distribution of payoffs should have a greater expected rate of return (and so lower prices) than less risky assets. The relation between risk-neutral and physical probabilities therefore depends on the price of risk; risk-neutral probabilities subsume, or incorporate, the effects of risk, since the prices from which they are calculated embed investors' risk preferences.

Like the physical density, the risk neutral density has first, second, third and fourth moments, respectively mean, variance, skewness and kurtosis. All densities are extracted from options and are therefore conditional and for a given horizon. In a risk-neutral density, the mean should correspond to the risk free rate at a given time with a particular maturity.

To estimate the higher moments of the (risk-neutral) density function of individual securities, we use the results in Bakshi and Madan (2000) and Bakshi, Kapadia, and Madan (2003). Bakshi and Madan (2000) show that any payoff to a security $i$ can be constructed and priced 
using a set of option prices with different strike prices on that security. They define $V_{i, t}(\tau)$, $W_{i, t}(\tau)$, and $X_{i, t}(\tau)$ as the time $t$ prices of $\tau$-maturity quadratic, cubic, and quartic contracts, respectively. Bakshi, Kapadia, and Madan (2003) define these contracts as contingent claims with payoffs equal to respectively future second, third and fourth powers of log price returns. The contracts are based on $C_{i, t}(\tau ; K)$ and $P_{i, t}(\tau ; K)$, which are the time $t$ prices of European calls and puts written on the underlying stock with strike price $K$ and expiration $\tau$ periods from time $t$. Expressions for $V_{i, t}(\tau), W_{i, t}(\tau)$, and $X_{i, t}(\tau)$ appear in Appendix A1 as equations (A1), (A2) and (A3). Using the prices of these contracts, standard moment definitions imply that the risk-neutral moments can be calculated as

$$
\begin{aligned}
V A R_{i, t}^{Q}(\tau) & =e^{r \tau} V_{i, t}(\tau)-\mu_{i, t}(\tau)^{2} \\
S K E W_{i, t}^{Q}(\tau) & =\frac{e^{r \tau} W_{i, t}(\tau)-3 \mu_{i, t}(\tau) e^{r \tau} V_{i, t}(\tau)+2 \mu_{i, t}(\tau)^{3}}{\left[e^{r \tau} V_{i, t}(\tau)-\mu_{i, t}(\tau)^{2}\right]^{3 / 2}} \\
K U R T_{i, t}^{Q}(\tau) & =\frac{e^{r \tau} X_{i, t}(\tau)-4 \mu_{i, t}(\tau) W_{i, t}(\tau)+6 e^{r \tau} \mu_{i, t}(\tau)^{2} V_{i, t}(\tau)-\mu_{i, t}(\tau)^{4}}{\left[e^{r \tau} V_{i, t}(\tau)-\mu_{i, t}(\tau)^{2}\right]^{2}}
\end{aligned}
$$

where

$$
\mu_{i, t}(\tau)=e^{r \tau}-1-e^{r \tau} V_{i, t}(\tau) / 2-e^{r \tau} W_{i, t}(\tau) / 6-e^{r \tau} X_{i, t}(\tau) / 24
$$

and $r$ represents the risk-free rate. We follow Dennis and Mayhew (2002), and use a trapezoidal approximation to estimate the integrals in expressions (A1) - (A3) using discrete data. ${ }^{2}$

In Table 1, we present descriptive statistics for the sample estimates of volatility, skewness, and kurtosis. We report medians, 5th and 95th percentiles across time and securities for each year during the sample period. The results in Table 1 indicate that higher moments are important in describing the risk-neutral distribution. While we do not conduct formal tests for the statistical significance of departures from normality, it is clear that there are individual stocks that are strongly negatively skewed (with fifth percentiles of skewness always smaller than -3 and medians as small as -1.3) and fat-tailed (with the 95th percentile of kurtosis in the cross section above 18 and medians consistently above 3). As Bakshi, Kapadia, and Madan (2003) point out, skewed risk-neutral distributions imply that the physical distribution is skewed, or fat-tailed, or both. In either case, the underlying physical distribution is non-Gaussian.

There are clear patterns in the time series of these moments through the sample period, as well as evidence of interactions between them. Volatility peaks in 2000, during the height of the Internet bubble, then declines through 2005. The median risk-neutral skewness is

\footnotetext{
${ }^{2}$ We are grateful to Patrick Dennis for providing us with his code to perform the estimation.
} 
negative, indicating that the distribution is left-skewed; the median value stays relatively flat through 2000 after which it declines sharply, while the median kurtosis estimate increases during that same period, more than doubling from 2000 through 2005 . In very broad terms, the results in Table 1 imply that the estimates of higher moments that we obtain using the Optionmetrics sample and the method of Bakshi, Kapadia, and Madan (2003) are related to price movements in the underlying market.

\section{Ex Ante Higher Moments and the Cross-section of Returns}

Our focus in this section is on testing whether estimates of the ex ante higher moments of the payoff distribution obtained from options data are related to the subsequent returns of the underlying security.

\subsection{Arbitrage Issues}

Under the assumption that no-arbitrage rules hold between the options market and the underlying security prices, the information set contained in both cash and derivatives markets should be the same. Several authors have shown that information in option prices can provide valuable forecasts of features of the payoff distributions in the underlying market. For example, Bates (1991) examines option prices (on futures contracts) prior to the market crash of 1987 and concludes that the market anticipated a crash in the year, but not the two months, prior to the October market decline. He also shows that fears of a crash increased immediately after the crash itself.

Our sample period includes the Internet bubble, and some researchers have argued that option prices and equity prices diverged during this period. For example, Ofek and Richardson (2003) propose that the Internet bubble is related to the 'limits to arbitrage' argument of Shleifer and Vishny (1997). This argument requires that investors could not, or did not, use the options market to profit from mis-pricing in the underlying market, and, in fact, they also provide empirical evidence that option prices diverged from the (presumably misvalued) prices of the underlying equity during this period. However, Battalio and Schultz (2006) use a different dataset of option prices than Ofek and Richardson (2003), and conclude that shorting synthetically using the options market was relatively easy and cheap, and that short-sale restrictions are not the cause of persistently high Internet stock prices. A corollary to their results is that option prices and the prices of underlying stocks did not diverge during the Internet bubble and they argue that Ofek and Richardson's results may be a consequence of 
misleading or stale price quotes in their options data set. Note that if option and equity prices do not contain similar information, then our tests should be biased against finding a systematic relation between estimates of higher moments obtained from option prices and subsequent returns in the underlying market. ${ }^{3}$ However, motivated by the Battalio and Schultz results, we employ additional filters to try to ensure that our results are not driven by stale or misleading prices. In addition to eliminating option prices below 50 cents and performing robustness checks with additional constraints on option liquidity, as mentioned above, we also remove options with less than one week to maturity, and eliminate days in which closing quotes on put-call pairs violate no-arbitrage restrictions.

\subsection{Portfolio Sorts}

Each day, we sample the prices of out of the money calls and puts on individual securities that have expiration dates that are closest to 0.083 years (one month), 0.250 years (three months), 0.500 years (six months) and 1.000 years to maturity and midpoint bid and offer prices of $\$ 0.50$ or greater. As documented in Dennis and Mayhew (2009), the procedure for calculating risk neutral moments is most accurate when we have an equal number of puts and calls. If there are a greater number of puts than calls, we retain only the same number of puts as we have calls. The puts that we retain in this circumstance are those that are closest to, but out of the money. We also require that there is trading volume in out of the money options for that firm at the selected maturity on the trading day. We then use the Bakshi, Kapadia, and Madan procedure outlined in section 2 to estimate volatility, skewness, and kurtosis for horizons of one, three, six, and twelve months. The resulting output of this procedure is a set of three risk neutral moments (volatility, skewness, and kurtosis) for four horizons each (one, three, six, and twelve months) for each firm on each day that data are available. At the daily frequency, a number of firms exhibit apparent outliers in measures of skewness and kurtosis, which appear to be the effect of data errors. We remove observations in the top $1 \%$ and bottom $1 \%$ of the cross-sectional distribution of volatility, skewness, and kurtosis each day to mitigate the effect of these outliers. Finally, we delete observations on firms that have less than 10 trading days of observations in a given calendar month.

Following Bakshi, Kapadia, and Madan (2003), we average the daily estimates for each stock over time (in our case, the calendar quarter). Thus, each firm in our sample has a single observation for volatility, skewness, and kurtosis for each maturity (one, three, six, and twelve months) over the period starting in the first quarter of 1996 and ending in the fourth

\footnotetext{
${ }^{3}$ Robert Battalio graciously provided us with the OPRA data used in their analysis; unfortunately, these data, provided by a single dealer, do not have a sufficient cross-section of data across calls and puts to allow us to estimate the moments of the risk-neutral density function in which we are interested.
} 
quarter of 2005. We rank each firm within the quarter on the basis of its maturity-dependent volatility, skewness, and kurtosis into terciles. The 'extreme' terciles contain $30 \%$ of the sample, while the middle tercile contains $40 \%$ of the sample. This sorting procedure results in twelve rankings per firm per quarter, on the basis of three moments and four maturities. We then use the rank to form equally-weighted portfolios over the subsequent calendar quarter, holding the moment tercile rank fixed. The result is a total of 36 portfolios ranked on horizondependent moments, with returns sampled at the monthly frequency over the period April, 1996 through December, 2005.

In Table 2, we report results for portfolios sorted on the basis of estimated volatility, skewness, and kurtosis. We focus on two maturity bins, 3 (Panel A) and 12 (Panel B) months; all other maturities are discussed in BLANK (2011). Specifically, we report the subsequent raw returns of the equally-weighted moment-ranked portfolios over the next month in the column with label 'Mean'. In the next column, we report the characteristic-adjusted return over that same month. To calculate the characteristic-adjusted return, we perform a calculation similar to that in Daniel, Grinblatt, Titman, and Wermers (1997). For each individual firm, we assess to which of the 25 Fama-French size- and book-to-market ranked portfolios the security belongs. We subtract the return of that Fama-French portfolio from the individual security return and then average the resulting excess or characteristic-adjusted 'abnormal' return across firms in the moment-ranked portfolio. In the next three columns of Table 2, we report the average firm's risk-neutral volatility, skewness and kurtosis estimates for each of the ranked portfolios.Finally, we report average betas, average (log) market value and average book-to-market equity ratios of the securities in the portfolio.

Summary statistics in Panel A of Table 2 imply a strong negative relation between volatility and subsequent raw returns; for example, in the 3 month maturity options, the returns differential between high volatility (Portfolio 3) and low volatility (Portfolio 1) securities is -56 basis points per month; longer 12 month maturities in Panel B have differentials of -69 basis points per month. The magnitude of this difference is not statistically significant; however, we speculate that this result is more due to the relatively small sample size (117 monthly observations) than a meaningful difference in the return differential across maturities. Low (high) volatility portfolios tend to contain low (high) beta firms and larger (smaller) firms, while differences in book-to-market equity ratios across portfolios are relatively small and differ across maturity bins. We adjust for these differences in size and book-to-market equity ratio in the characteristic-adjusted return column. After adjusting for the differences in size and bookto-market equity observed across the volatility portfolios, the return differentials are smaller. However, although the differential is reduced, it remains economically significant, with the lowest volatility portfolios earning -36 (-44) basis points, for 3 (12) month maturity options, 
per month more than the highest volatility portfolios.

There is virtually no relation between volatility and skewness estimates in the sample. The relation between volatility and kurtosis is much stronger: as average volatility increases in the portfolio, kurtosis declines. Thus, the relation between volatility and returns may be confounded by the effect, if any, of other moments on returns; we examine this possibility later in this section. Finally, the average number of securities in each portfolio indicates that the portfolios should be relatively well-diversified. The top and bottom tercile portfolios average 92 firms, whereas the middle tercile portfolio averages 123 firms. Combined with the fact that we are sampling securities which have publicly traded options, this breadth should reduce the effect of outlier firms on our results.

Most interestingly, we see significant differences in Table 2 in returns across skewnessranked portfolios. The raw returns differential is negative for 3 and 12 months maturities, at -82 and -73 basis points per month, respectively. That is, on average, in each maturity bin the securities with lower skewness earn higher returns in the next month, while securities with less negative, or positive, skewness earn lower returns. The differentials in raw returns are of the same order of magnitude and somewhat larger than those observed in the volatilityranked portfolios, and the difference is statistically different than zero at the $10 \%$ or better critical level. Compared to the volatility-ranked portfolios, the skewness-ranked portfolios show relatively little difference in their betas, and comparable differences in their market value and book-to-market equity ratios. When we adjust for the size- and book-to-market characteristics of securities, the characteristic-adjusted returns hardly change, averaging -79 and -67 basis points per month, respectively, across the two maturity bins. ${ }^{4}$

In addition to the differences in returns, the table indicates that there is a negative relation between skewness and kurtosis. That is, kurtosis declines as we move across skewnessranked portfolios. As in Panel A, interactions between other moments and returns could be masking or exacerbating the relation between skewness and returns. Consequently, in later tests, we control for the relation of other higher moments to returns in estimating their effect.

\footnotetext{
${ }^{4}$ In a different application, Xing, Zhang, and Zhao (2010) find a positive relation between a skewness metric taken from option prices and the next month's returns. Their measure of skewness is the absolute value of the difference in implied volatilities in out-of-the-money call option contracts, where the strike price is constrained to be within the range of $0.8 S$ to $S$, (where $S$ is the current price of the underlying stock), and preferably in the range of $0.95 S$ to $S$. Thus, their skewness measure is related to the slope of the volatility smile over a smaller range of strike prices. We conduct a Monte Carlo exercise using a Heston model with plausible parameter values, to compare the performance of our skewness metric to theirs in a setting where skewness is known. In this controlled environment we find that the slope estimate of skewness used by Xing et al. is extremely noisy (using a Mean Squared Error metric) compared to the Bakshi et al. approach we use. The simulation details are reported in BLANK (2011).
} 
Both panels in Table 2 also report the results when securities are sorted on the basis of estimated kurtosis. Generally, we see a positive relation between kurtosis and subsequent raw returns; the return differential is economically significant, at approximately 72 basis points per month across each of the two maturities. As with the other moment-ranked portfolios, the effect is reduced after adjusting for book-to-market and market capitalization differences, but the differences are very slight and the effect remains highly economically significant across the two maturity bins and statistically significant at the 5\% critical level. As in the other panels, we also observe patterns in the other estimated moments, with both volatility and skewness decreasing as kurtosis increases. ${ }^{5}$

\subsection{Multivariate sorts}

We estimate the relation between higher moments and subsequent returns, while controlling for variation in other higher moments, using double and triple sorts. ${ }^{6}$ In the double-sorting method, we sort firms into tercile portfolios based independently on volatility, skewness, and kurtosis. We then form portfolios based on the intersection of rankings of volatility and either skewness or kurtosis. ${ }^{7}$ For each of the nine portfolios formed, we report subsequent returns. The results from sorting on volatility and skewness, for three-month and twelve-month options, are reported in Panel A of Table 3; the results from sorting on volatility and kurtosis are reported in Panel B. In each Panel, the number of firms in each portfolio are reported in parentheses below the returns.

Reading across the columns of Panel A in Table 3, we observe that, holding volatility constant, skewness continues to be negatively related to subsequent returns for all levels of volatility and for both maturities. The effect is monotonic in 4 out of 6 cases and the return differential across the extreme skewness terciles varies from -19 to -100 basis points per month. This magnitude is roughly consistent with the magnitude of the return differential in univariate sorted portfolios in Table 2. The table also highlights the fact that the negative relation between risk-neutral volatility and subsequent returns is found primarily in the middle and

\footnotetext{
${ }^{5}$ We also re-calculated our results using value- rather than equal-weighting, and found similar differentials for skewness and kurtosis, although the sign of the volatility relation is reversed for options at most maturities. For example, in volatility sorted portfolios, spreads for 1, 3, 6 and 12 month options are 10, 39, -20 and 17 bp per month, respectively. For skewness-sorted portfolios, spreads are consistently negative and of similar magnitude across maturities; for kurtosis-sorted portfolios, we continue to observe positive differentials, although they vary somewhat more in magnitude across option maturities.

${ }^{6}$ We explored the use of Fama-MacBeth regressions to estimate the effect of variation in individual higher moments, while holding other moments constant, at the individual firm level. Unfortunately, the number of firms combined with the noise in the moment estimates provided insufficient power to draw reliable inferences about the relations between moments and returns.

${ }^{7}$ Sorts on skewness and kurtosis resulted in portfolios that were too sparse to make inferences; empirically, it's rare to observe very skewed distributions (in either direction) that do not have high kurtosis.
} 
high skewness firms.

In Panel B, where we sort on volatility and kurtosis, the results are also generally consistent with the univariate kurtosis sorts in Table 2. In five out of six cases, holding volatility constant, the return differential in extreme kurtosis portfolios is positive, and varies between 4 and 86 basis points per month. In the sixth case (moderate volatility portfolios and threemonth options), the return differential is a negative 24 basis points per month. The negative relation between risk-neutral volatility and subsequent returns occurs largely among firms with relatively low (tercile 1 ) or high (tercile 3 ) kurtosis firms.

We also perform a multivariate independent sort on all three higher moment estimates. Clearly, the number of firms in each of the portfolios would decline sharply if we form tercile portfolios for each moment, and many portfolios would be empty. As a consequence, for the triple sort, we sort into two portfolios only. These results are presented in Panel C of Table 3. While the number of firms in some portfolios is relatively small, the results are fairly clear. If we hold skewness and kurtosis levels constant, we continue to see a negative relation between volatility and subsequent returns. In 7 out of 8 cases, the differential is negative, varying between -11 and -50 basis points per month. If we hold volatility and kurtosis constant, we continue to see a negative relation between skewness and subsequent returns, with the differential varying between -14 and -68 basis points per month. However, when we control for both volatility and skewness, the kurtosis effect does not appear to be stable. In six of the eight cases, increasing kurtosis is associated with a decline in returns, with the magnitude of the return differential varying from -32 to -3 basis points. In the remaining two cases, the effect of increasing kurtosis is positive (at 1 and 28 basis points per month, respectively).

Overall, the results in Table 2 and Table 3 imply that, on average, higher moments in the distribution of securities' payoffs are related to subsequent returns. Consistent with the evidence in Ang, Hodrick, Xing, and Zhang (2006), we see that securities with higher volatility have lower subsequent returns. We also find that securities with higher skewness have lower subsequent returns. Finally, while higher kurtosis is related to higher subsequent returns in individual sorts, this effect is not robust when controlling for variation in volatility and skewness.

The evidence that the relation between kurtosis and returns is relatively weak compared to skewness is consistent with the evidence in Chang, Christoffersen, and Jacobs (2009). In addition, the evidence that skewness in individual securities is negatively related to subsequent returns is consistent with the models of Barberis and Huang (2008), and Brunnermeier, Gollier, and Parker (2007). In their papers, they note that investors who prefer positively skewed distributions may hold concentrated positions in securities whose payoffs are more 
right-skewed - that is, investors may trade off skewness against diversification, since adding securities to a portfolio will increase diversification, but at the cost of reducing skewness. The preference for skewness will increase the demand for, and consequently the price of, securities with higher skewness and consequently reduce their expected returns. The magnitude of the differential for skewness that we find is consistent with the empirical results in Boyer, Mitton, and Vorkink (2010), who generate a cross-sectional model of expected skewness in physical distributions for individual securities and find that portfolios sorted on expected skew generate a return differential of approximately 67 basis points per month. Finally, our results in monthly returns are consistent with the longer-horizon results of Green and Hwang (2009), who find that, while IPOs with high expected skewness have significantly greater first day returns, they tend to earn significantly lower returns over the next 3-5 years.

Despite the fact that the negative relation between skewness and returns, for which we find evidence, is consistent with behavioral explanations as in citeasnounbarberis2007stocks, it does not follow that we can rule out rational explanations. For example, in an analysis of investors who optimize over mean, variance, skewness and kurtosis of returns, Chabi-Yo, Ghysels, and Renault (2010) show that allowing for heterogeneity in investors' preferences and beliefs can give rise to additional factors (beyond co-moments) in the pricing of nonlinear risks. And, Mitton and Vorkink (2007) show that allowing for heterogeneity in investors' preferences for skewness can also lead to right-skewed securities having higher prices.

\subsection{Factor-Adjusted Returns}

In Table 2, we adjust for the differences in characteristics across portfolios, following Daniel, Grinblatt, Titman, and Wermers (1997), by subtracting the return of the specific Fama-French portfolio to which an individual firm is assigned. However, Fama and French (1993) interpret the relation between characteristics and returns as evidence of risk factors. Consequently, we also adjust for differences in characteristics across our moment-sorted portfolios by estimating a time series regression of the High-Low portfolio returns for each moment on the three factors proposed in Fama and French (1993).

Results of this risk adjustment are reported in Table 4. The dependent variables in our regressions are the monthly returns from portfolios re-formed each month (as in Table 2), where the portfolios are either the tercile sorts or a long position in the portfolio of securities with the highest estimated moments, and a short position in the portfolio of securities with the lowest estimated moments. The three factors in the regressions are the return on the valueweighted market portfolio in excess of the risk-free rate $\left(r_{M R P, t}\right)$, the return on a portfolio of small capitalization stocks in excess of the return on a portfolio of large capitalization stocks 
$\left(r_{S M B, t}\right)$, and the return on a portfolio of firms with high book-to-market equity in excess of the return on a portfolio of firms with low book-to-market equity $\left(r_{H M L, t}\right)$. Since the dependent portfolios in our analysis are equally-weighted, we construct factors on the basis of equallyweighted portfolio returns as well. Firms are again grouped by maturity and sorted into portfolios on the basis of estimated moments (volatility, skewness and kurtosis) using options closest to three and twelve months to maturity, respectively. ${ }^{8}$ We report in Table 4 intercepts, slope coefficients for the three factors, and adjusted R-squareds. Tests statistics for the null hypothesis that the coefficient is zero are presented below the point estimates.

The first panel in Table 4 contains the results for volatility-sorted portfolios. Consistent with the results in Table 2 for characteristic-adjusted returns, we observe negative alphas in our "high-low" portfolio. The point estimates of the intercepts suggest that risk adjustment has little economic impact on the magnitude of the returns to the portfolios. Alphas for zerocost portfolios sorted on the basis of 3-month (12-month) options earn alphas of -48 (-56) basis points. While the point estimates are not statistically distinguishable from zero, we conjecture that this result is again due to a relatively small sample size rather than the precision of the estimates. The magnitude and sign of these excess returns are consistent with those of Ang, Hodrick, Xing, and Zhang (2006), who show that firms with high idiosyncratic volatility relative to the Fama-French model earn "abysmally low" returns.

The patterns in the intercepts for skewness-sorted portfolios are of the same sign as the volatility-sorted alphas but larger in magnitude and statistically significant at the 5\% level. For 3-month (12-month) maturity options, the results indicate that a zero cost portfolio earns -110 (-103) basis points per month relative to Fama-French risk adjustment. These findings are consistent with the summary statistics in Table 2. The negative alphas still imply a 'low skewness' premium; that is, securities with more negative skewness earn, on average, higher returns in the subsequent months, while securities with less negative, or positive skewness, earn lower returns in subsequent months.

We also report in Table 4 the results for kurtosis-sorted portfolios. The economic magnitude and statistical significance of the zero-cost portfolio alphas are highest for this set of portfolios. For 3-month (12-month) options, we observe excess returns of 118 (117) basis points per month, statistically distinguishable from zero at the $1 \%$ critical level. Consistent with the results in Table 2, we see positive intercepts in portfolios that are long kurtosis. The magnitude of the alphas with respect to kurtosis is comparable to that observed in the skewness and volatility sorted portfolios.

There is one other noteworthy feature of Table 4. The explanatory power of the Fama-

\footnotetext{
${ }^{8}$ The one and six month maturities - reported in BLANK (2011) - yield similar findings.
} 
French three factors is, on average, lower for the kurtosis-sorted High-Low portfolios, and much lower for the skewness-sorted High-Low portfolios, than the volatility-sorted portfolios. Some of this difference is likely due to the fact that, as Table 2 shows, skewness and kurtosissorted portfolios exhibit much smaller differences in size and beta than do the volatility-sorted portfolios. However, it is also possible that there are features of the returns on moment-sorted portfolios that are not captured well by the usual firm characteristics. This evidence implies that there is potentially important variation in the returns of higher moment sorted portfolios that is not captured by the Fama and French (1993) risk adjustment framework.

Recall that the evidence from the multivariate sorts in Section 3.3 indicated that, while moment estimates are correlated, the effects of volatility and skewness are robust to controlling for variation in other moments; kurtosis effects were, in contrast, much weaker after controlling for variation in volatility and skewness. The results in Table 4 are also informative in this regard. The distinct pattern of pricing errors, and in particular the differences in explanatory power of Fama-French factors between volatility sorts on the one hand, and skewness (and to a lesser extent kurtosis) sorts on the other, indicate that our results are not driven exclusively by confounding effects across moment classifications.

\subsection{Robustness checks}

As noted above, one of our concerns following the findings of Battalio and Schultz (2006) is that results might be driven by stale or misleading prices. Consequently, as a robustness check, we perform other tests to examine the possibility that return differentials are driven by liquidity issues, either in the underlying equity returns or by stale or illiquid option prices. For example, we consider alternative minimum price criteria for the options included in our sample. We also risk-adjust returns relative to an aggregate liquidity factor, as in Pástor and Stambaugh (2003). The results presented in this section are robust to these additional requirements, and are discussed in more detail in BLANK (2011).

\section{Higher Moment Returns: Systematic and Idiosyncratic Com- ponents}

In this section, we analyze the extent to which the cross-sectional relations between higher moments and returns presented in Tables 2 and 4 are due to investors seeking compensation for higher co-moment risk, rather than idiosyncratic moments. We start in subsection 4.1 with a characterization of co-skewness and co-kurtosis in the context of single factor models, 
inspired by the analysis in Harvey and Siddique (2000) and Bakshi, Kapadia, and Madan (2003). In subsection 4.2 , we estimate the relation of risk-neutral co-moments to returns in our sample. In subsection 4.3 we decompose total moments into co-moments and idiosyncratic moments and examine the relationship of these components to subsequent returns. In a final subsection we report on various robustness checks using more general specifications.

\subsection{Co-skewness, Co-kurtosis and a Single Factor Model}

Bakshi, Kapadia, and Madan (2003) suggest a procedure for computing the co-skewness of an asset with a factor. They assume a single factor data-generating process:

$$
r_{i, t}=a_{i}+b_{i} r_{m, t}+e_{i, t}
$$

where $e_{i, t}$ is assumed to be independent of $r_{m, t}$. The authors note that if the parameters $a$ and $b$ are 'risk-neutralized', equation (5) is also well-defined under the risk-neutral measure. With this single factor model, co-skewness can be calculated as:

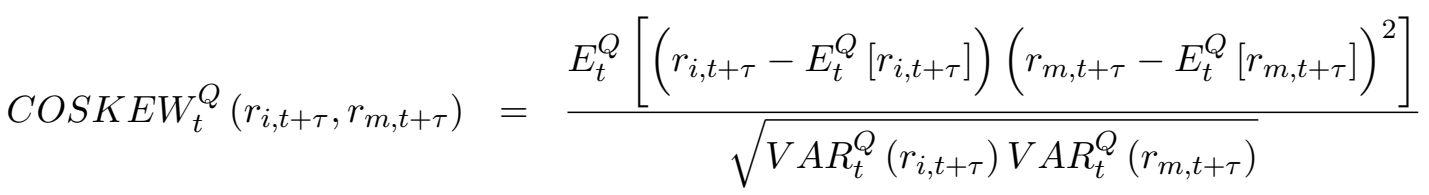

$$
\begin{aligned}
& =b_{i} S K E W_{m, t}^{Q}(\tau) \frac{V A R_{i, t}^{Q}(\tau)}{\sqrt{V A R_{m, t}^{Q}(\tau)}}
\end{aligned}
$$

In these expressions, $r_{i, t+\tau}$ is the $\tau$-period return on the underlying security, $S K E W^{Q}$ is the risk-neutral skewness, and $C O S K E W^{Q}$ is the risk-neutral co-skewness with the single factor $m$. Note that the formula in equation (6) is the risk neutral equivalent of the co-skewness measure used by Harvey and Siddique (2000) (see their equation (11) and equations (26)-(27) in Bakshi, Kapadia, and Madan (2003)).

A similar argument can be invoked to derive co-kurtosis,

$$
\begin{aligned}
\operatorname{COKURT}_{t}^{Q}\left(r_{i, t+\tau}, r_{m, t+\tau}\right) & =\frac{E_{t}^{Q}\left[\left(r_{i, t+\tau}-E_{t}^{Q}\left[r_{i, t+\tau}\right]\right)\left(r_{m, t+\tau}-E_{t}^{Q}\left[r_{m, t+\tau}\right]\right)^{3}\right]}{V A R_{t}^{Q}\left(r_{i, t+\tau}\right) V A R_{t}^{Q}\left(r_{m, t+\tau}\right)} \\
& =b_{i} \frac{K U R T_{m, t}^{Q}(\tau)}{V A R_{i, t}^{Q}(\tau) V A R_{m, t}^{Q}(\tau)}
\end{aligned}
$$

Since $b_{i}$ is a risk-neutral parameter in equations (6)-(7), Bakshi, Kapadia, and Madan (2003) 
note that it can be estimated from options data. Accordingly, we estimate $b_{i}$ using the procedure in Coval and Shumway (2001). Specifically, we compute the risk-neutral $b_{i}$ as:

$$
b_{i}=\frac{S_{i, t}}{C_{i, t}} \mathcal{N}\left(\frac{\ln \left(S_{i, t} / K_{i}\right)+\left(r-\delta+0.5 \sigma^{2}\right) \tau}{\sigma \sqrt{\tau}}\right) \beta_{i}
$$

where $\mathcal{N}$ represents the normal distribution, $\delta$ is the stock's dividend yield, $\sigma^{2}$ is the volatility of the underlying stock return, and $\beta_{i}$ is the slope coefficient from a projection of underlying stock returns on the single factor. ${ }^{9}$ We estimate $\beta_{i}$ using one year of past daily returns to the underlying equity, regressed on the S\&P500, ending on the day of the observed option prices. To avoid cross-sectional biases in $\beta$ related to cross-sectional variation in liquidity, we use the procedure in Dimson (1979) that corrects for infrequent trading; our reported results use a 1-day lead and lag of the market return as additional regressors. In unreported results, we also computed Dimson $\beta$ 's with 5 leads and lags of the market return, and found very little difference in the results.

\subsection{Relation of risk-neutral co-moments to returns}

Given estimates of $b_{i}$, we compute co-skewness and co-kurtosis using equations (6) and (7); note that the estimate of $b_{i}$ corresponds directly to a measure of risk-neutral covariance with the single factor $m$. Previous authors, such as Harvey and Siddique (2000) and Dittmar (2002), have reported significant cross-sectional relationships between physical co-moments and returns. We examine whether there are similar relationships between risk-neutral comoments and expected returns. We form co-moment sorted portfolios which are analogous to the total moment sorted portfolios used in Table 2 . That is, we first calculate daily risk-neutral co-moments. We average these co-moments over the calendar quarter, rank into terciles and then form equal-weight portfolios on the basis of these rankings over the next three months. Reported results in Table 5 have the same structure as the results for total moments reported in Table 2.

The risk-neutral covariance sorted portfolios are associated with a positive premium of 41 basis points per month for 3-month options and 65 basis points for 12 -month maturity options. This premium is reversed in sign, and roughly similar in magnitude, to the total volatility premium reported in Table 2 . The premium is substantially attenuated when we

\footnotetext{
${ }^{9}$ Coval and Shumway (2001) report that their estimates of $b_{i}$ following this procedure are very similar to those calculated by directly regressing option returns on the market portfolio. We follow their lead, and use the average ratio of $S_{i, t} / C_{i, t}$ across calls and the risk neutral variance calculated for each security $i$ to compute our estimates of this parameter. We also experimented with using the most and least out-of-the-money calls in our estimates and found little cross-sectional sensitivity to the choice of call options.
} 
adjust for firm characteristics; it is reduced to $14 \mathrm{bp}$ (36 bp) for 3 (12) month options. This indicates that, similar to the total volatility premium, differences in risk-neutral covariances are associated with significant differences in market capitalization and book-to-market equity ratios.

Differences in co-skewness are associated with significant negative differences in returns of 48 basis points for three-month options, and 64 basis points for 12 month options. The magnitude of this differential is of the same sign, and similar in magnitude to, the co-skewness premium reported in Harvey and Siddique (2000); they find a negative premium associated with co-skewness of approximately 30 basis points per month. Adjusting for firm characteristics significantly reduces the co-skewness premium, to -16 basis points for three-month options and -29 basis points for 12-month options. These results are also broadly consistent with Harvey and Siddique (2000), who link co-skewness to characteristics such as size and book-to-market equity.

Finally, portfolios sorted on co-kurtosis are associated with a positive return differential that is similar in sign and magnitude to portfolios sorted on total kurtosis. When measured using 3-month (12-month) maturity options, the difference in returns is 55 (54) basis points per month. Co-kurtosis is also associated with firm characteristics, and as a consequence these return differentials are also significantly reduced after characteristic adjustment, with characteristic-adjusted returns falling to 25 basis points per month for both option maturities. Although economic magnitude of covariance, coskewness, and cokurtosis premia seem significant, the statistical evidence does not indicate that these premia are significantly different than zero at conventional critical levels.

Overall, our estimates of risk-neutral co-moments appear to generate dispersion in returns that are consistent with the relation between physical co-moments and returns observed by other researchers. In addition, these risk-neutral co-moments are strongly associated with differences in firm characteristics. This association with characteristics may be due to the comoments' representations of common factor exposures. Table 6 reports the results of time series regressions of the co-moment sorted High-Low portfolio returns on the three factors proposed in Fama and French (1993) as in Table 4. In sharp contrast to the results in Table 4 on moment-sorted portfolios, all of the alphas in Table 6 are insignificant, and the R-squares for co-skewness and co-kurtosis sorted portfolios are substantially higher than the R-squares for skewness and kurtosis sorted portfolios. These results imply that a significant fraction of the returns differential in Table 2 is associated with the idiosyncratic component of higher moments, rather than co-moments with the market portfolio. We explore this further in the next section. 


\subsection{Decomposing total moment return effects}

We decompose the return differential observed for total moment sorted portfolios in Table 2, into components related to dispersion in co-moments and dispersion in idiosyncratic moments. We begin by regressing the daily series of total moments for each firm on daily co-moments within the calendar quarter:

$$
\begin{gathered}
\mathcal{V}_{i, t}^{Q}=\kappa_{0 i}^{\mathcal{V}}+\kappa_{1 i}^{\mathcal{V}} C O V A R_{i, t}^{Q}+\zeta_{i, t}^{\mathcal{V}} \\
\mathcal{S}_{i, t}^{Q}=\kappa_{0 i}^{\mathcal{S}}+\kappa_{1 i}^{\mathcal{S}} C O S K E W_{i, t}^{Q}+\zeta_{i, t}^{\mathcal{S}} \\
\mathcal{K}_{i, t}^{Q}=\kappa_{0 i}^{\mathcal{K}}+\kappa_{1 i}^{\mathcal{K}} C O K U R T_{i, t}^{Q}+\zeta_{i, t}^{\mathcal{K}}
\end{gathered}
$$

In this specification, idiosyncratic moments are the intercepts, $\kappa_{0 i}^{\mathcal{V}}, \kappa_{0 i}^{\mathcal{S}}$, and $\kappa_{0 i}^{\mathcal{K}}$, or the portion of the total moments that are not explained by co-moments. ${ }^{10}$ While the relation between total moments and co-moments in the regressions above is significant, the explanatory power of the co-moments is not large.

Following the procedure for the total moments and co-moments above, we sort firms into tercile portfolios on the basis of the idiosyncratic moments. Summary statistics for these portfolios are presented in Table 7, and regressions adjusting for the contribution of Fama and French risk factors to returns are presented in Table 8. These tables have the same structure as Tables 2 and 4 in which we sort firms into portfolios on the basis of total moments.

The results in Tables 7 and 8 mimic to a large extent the total moment results reported in Tables 2 and 4. That is, while risk-neutral co-moments have significant relations to returns that are consistent with the relations found in physical co-moments by other authors, and while we do find dispersion in co-moments in portfolios sorted on total moments, the returns differentials associated with differences in idiosyncratic moments are not substantially different than those observed in total moments in Table 2, and the alpha estimates obtained after Fama-French risk adjustment for idiosyncratic moments are not substantially different than those for total moments. In general, differences in idiosyncratic moments appear to drive most of the dispersion in total moments, and the returns differential associated with differences in idiosyncratic moments is both statistically and economically significant.

\footnotetext{
${ }^{10}$ Note that within the quarter, the average errors must be equal to zero; as a consequence, including the residual in the average idiosyncratic moment would not change our results.
} 


\subsection{Robustness}

The analysis in the previous subsections relied on the assumption of a single-factor datagenerating process. As a robustness check, we explore other approaches to the specification of systematic risks. We will describe these results briefly here; they are available in BLANK (2011).

We consider alternative specifications of the stochastic discount factor, $M_{t}(\tau)$, where $M_{t}(\tau)$ satisfies the Euler equation

$$
E_{t}\left[M_{t}(\tau) r_{i, t}(\tau)\right]=0
$$

and $r_{i, t}$ is an excess return for asset $i$. In this setting, inferences about the importance of idiosyncratic moments are relative to a particular specification of the stochastic discount factor. Failure of the Euler equation condition to hold may represent the importance of idiosyncratic risk or mis-specification of the stochastic discount factors.

We use several methods to estimate $M_{t}(\tau)$ that allow for higher co-moments to influence required returns. These methods differ in the details of specific factor proxies, the number of higher co-moments allowed, and the construction of the stochastic discount factor. The goal in each case is to estimate the relation between idiosyncratic moments and residual returns, after adjusting for risk.

We begin by considering a parametric stochastic discount factor (SDF) that incorporates information about higher moments of the SDF, and consequently adjusts for securities' comoment risk with the SDF. This approach is similar to that of Harvey and Siddique (2000) and Dittmar (2002), who examine polynomial stochastic discount factors that account for coskewness and co-kurtosis risk, respectively. The evidence from these tests suggests that the payoffs to higher moment-sorted portfolios, particularly skewness-sorted portfolios, cannot be traced to higher co-moments with respect to a value-weighted market proxy. While the statistical magnitude of the pricing errors is not consistent across all specifications, the economic magnitude of the pricing errors is large. As a consequence, relative to the risks associated with returns on an S\&P 500 tangency portfolio, the returns to the moment-sorted high minus low portfolios appear to be idiosyncratic.

In a second specification of $M_{t}(\tau)$, we estimate the parameters of the SDF polynomial using the returns on the tangency portfolio, where the basis assets used to construct the tangency portfolio consist of industry portfolios. This specification yields similar results to those obtained with the S\&P 500. Finally, we consider a non-parametric estimate of $M_{t}(\tau)$, in which we construct the SDF by taking the ratio of the risk-neutral distribution of the market portfolio, constructed from index options data, to estimates of the physical distribution 
constructed from different samples of historical returns data. Although the precision of the estimates is poor, the results of this method are again similar, with idiosyncratic moments, particularly skewness, still significantly related to subsequent returns.

Overall, the results of our robustness analysis appear to corroborate the evidence we obtain using a simple single-factor model. This evidence indicates that the payoffs of momentsorted portfolios are less related to systematic exposure to a stochastic discount factor than they are to idiosyncratic components.

\section{Risk Neutral and Physical Probability Distributions}

Up to this point, we have focused on the estimation of risk-neutral moments, and the relationship with subsequent returns. However, the models, such as Barberis and Huang (2008) and Brunnermeier, Gollier, and Parker (2007) that consider the effects of skewness and fat tails in individual securities' distributions on expected returns deal with investors' estimates of the physical distribution. The purpose of this section is to analyze the relation between risk-neutral and physical moments in our sample, and whether the predictive power of riskneutral moments for subsequent returns is due to their relation to physical moments. In addition, we examine the relation between risk-neutral moments and forward-looking valuation ratios.

\subsection{Risk-neutral moments, physical moments and subsequent returns}

Bakshi, Kapadia, and Madan (2003), who examine the relation between risk-neutral and physical distributions, note that under certain conditions the risk-neutral distribution can be obtained by simply exponentially 'tilting' the physical density, with the tilt determined by the risk-aversion of investors. Related, Bliss and Panagirtzoglou (2004) assume a timevarying stationary risk-aversion function and use estimates of the risk-neutral distribution taken from option prices, and a particular parametric form of the utility function, to estimate physical distributions. While time variation in risk premia or, equivalently risk aversion, may cause differences between risk-neutral and physical distributions over longer intervals, these papers suggest that, with a relatively constant pricing kernel over shorter periods, the crosssectional variation in risk-neutral and physical moments will capture the same information.

We compute risk neutral skewness using the standard measure based on the third moment of returns. It would therefore be natural to compute the physical measure third moments by using sample third moments to measure skewness. However, it is well-known that skewness 
estimates based on sample averages are sensitive to outliers, even more so than are estimates of the first two moments. This fact has prompted researchers since Pearson (1895), Bowley (1920), and more recently Hinkley (1975) to look for robust measures of asymmetry that are not based on sample estimates of the third moment. Specifically, Hinkley's (1975) robust coefficient of asymmetry (skewness) is defined as:

$$
R A_{\theta}\left(r_{t}\right)=\frac{\left(q_{\theta}\left(r_{t}\right)-q_{0.50}\left(r_{t}\right)\right)-\left(q_{0.50}\left(r_{t}\right)-q_{1-\theta}\left(r_{t}\right)\right)}{q_{\theta}\left(r_{t}\right)-q_{1-\theta}\left(r_{t}\right)}
$$

where $q_{1-\theta}\left(r_{t}\right), q_{0.50}\left(r_{t}\right)$ and $q_{\theta}\left(r_{t}\right)$ are the $1-\theta, 0.5$, and $\theta$ quantiles of $r_{t}$, and quantile $\theta$ is defined as $q_{\theta}\left(r_{t}\right)=F_{n}^{-1}\left(r_{t}\right)$, for $\theta \in(0,1] .{ }^{11}$ This skewness measure captures asymmetry of quantiles $q_{1-\theta}\left(r_{t}\right)$ and $q_{\theta}\left(r_{t}\right)$ with respect to the median (i.e. $q_{0.50}\left(r_{t}\right)$ ). In the specific case of $\theta=0.75$, we are considering the inter-quartile range and, in that case, (10) is known as Bowley's (1920) statistic. The normalization in the denominator ensures that the measure is unit independent with values between -1 and 1 . When $R A_{\theta}\left(r_{t}\right)=0$ the distribution is symmetric, while values diverging to -1 (1) indicate skewness to the left (right).

Two types of applications of the above measure have been proposed and used in the finance literature. Kim and White (2004), White, Kim, and Manganelli (2008) and Ghysels, Plazzi, and Valkanov (2011) adopt the above measure in a time series context, whereas Zhang (2006), Green and Hwang (2009) apply the $R A$ measure in a cross-sectional context. We pursue the cross-sectional approach and analyze the relationship between physical and risk neutral skewness across securities.

The approach of Zhang (2006) consists of pooling a cross-section of stocks along some common characteristic. Since we are interested in studying the match between risk neutral and physical measure skewness, we use risk neutral skewness as the characteristic, and pool firms within quantiles on the basis of risk-neutral skew. Specifically, we rank firms into three groups on the basis of risk neutral skew. Within each group, we calculate the quantile-based skewness measure appearing in equation (10) using monthly returns compounded over the six months ending in the calendar quarter. Each risk neutral tercile $k$ will then have a measure of average risk-neutral skew, $S_{k, t}^{Q}$, and a measure of physical skew, $S_{k, t}^{P}$. We use this information to compute frequency tables to assess the frequency with which the risk-neutral skew ranking is equal to the physical skew ranking. Under the hypothesis that the rankings assign firms randomly to each tercile, the frequency with which a first tercile risk neutral skew firm is a first tercile physical skew firm is $33.3 \%$.

The results of this tabulation are presented in the left-most sections of Table 9, with results

\footnotetext{
${ }^{11}$ The inverse of $F\left(r_{t}\right)$ is unique when it is assumed that $F\left(r_{t}\right)$ is strictly increasing. If $F\left(r_{t}\right)$ is not strictly increasing, then we can define the quantile as $q_{\theta_{k}}^{*}\left(r_{t}\right) \equiv \inf \left\{r: F_{n}\left(r_{t}\right)=\theta_{k}\right\}$.
} 
using 3-month options in Panel A and 12-month options in Panel B. In both sets of results, the assignment between $P$ and $Q$ measures of skewness appears to be non-random. Particularly in the first and third terciles, there is a propensity for low risk neutral skew firms to have low physical skewness (48\% and $48 \%$ for 3- and 12-month maturities), and for high risk neutral skew firms to have high physical skewness (42\% and $44 \%$ for 3 - and 12 -month maturities). While the propensity is somewhat lower for firms with intermediate skew, the ratio still exceeds the null of random assignment of 33.3\%. A formal test of this null hypothesis is presented below each table; the $\chi^{2}$ test of the null suggests strong rejection of the hypothesis of random assignment across terciles. Despite this evidence, while the diagonal elements are dominant, it is also clear that the mapping between $Q$ and $P$ is not perfect.

We next ask whether the variation in average returns that we observe due to risk neutral skewness is more closely associated with the risk neutral skewness or physical skewness classification. Our approach to answering this question is similar to the contingency table results above. We begin with the risk-neutral terciles from our previous analysis. To generate dispersion in physical skewness within each tercile, we further subdivide each tercile into four groups on the basis of risk-neutral skew. We calculate the quantile-based physical skewness within each of these twelve groups, and then, conditional on the risk-neutral tercile ranking, sort on the basis of physical skewness into three groups. ${ }^{12}$ As a result, we're left with nine classifications of securities, based on risk-neutral and physical skewness. We form equallyweighted portfolio returns of these nine classifications.

Average returns for the portfolios appear in the second set of panels in Table 9. For the purposes of comparison, recall that the results in Table 2 generate a skewness 'discount' of $0.82 \%(0.73 \%)$ per month for 3 (12) month maturity options. In the mean returns panel of Table 9, holding physical skew constant, we continue to see average return differentials that decline as risk-neutral skewness increases (reading down each column). However, holding risk-neutral skewness constant (in each row), there is no clear pattern in average returns as physical skewness increases. For example, in the sample of 3 month options, for low riskneutral portfolios, the average returns increases by 49 basis points per month as physical skew increases. For moderate risk-neutral portfolios, the returns are basically flat as physical skew increases, and for high risk-neutral portfolios, returns decrease by $0.30 \%$ per month.

Overall the results in Table 9 tell us that there is an association between $Q$ and $P$ skewness measures, but that they are far from perfectly related. One advantage of risk neutral skewness is that it is truly a market-based forward looking prediction, while the skewness

\footnotetext{
${ }^{12}$ The three groups are 1) securities with 'extreme' high physical skewness 2) securities with 'extreme' low physical skewness and 3) securities in the middle two groups of physical skewness. Using twelve groups helps us balance consideration between generating sufficient dispersion in physical skewness and having a sufficient number of firms in each group.
} 
measure under $P$ that we have used is historical in nature - and therefore may not have the same predictive content. One could potentially invoke parametric prediction models for skewness under $P$, such as those proposed by Harvey and Siddique (1999). In general, however, it is a challenging task to estimate such time series models for individual firms. In such a setting, the use of option prices eliminates the need of a long time series of returns to estimate the moments of the return distribution.

\subsection{Skewness, Valuation and the Internet Bubble}

We have presented evidence that risk-neutral higher moments are associated with crosssectional variation in subsequent returns, and that a significant portion of this explanatory power is due to idiosyncratic moments. We have also shown in Table 9 that risk-neutral and physical moments are related, although the predictive power of physical measures, after controlling for risk-neutral moments, is relatively weak. In this section, we analyze the relation between higher risk-neutral moments and valuation ratios. Valuation ratios should, in equilibrium, be the (inverse of the) infinite sum of discounted expected future cash flows. As a consequence, they also represent beliefs at time $t$ about future payoffs. Such a question may be particularly interesting during the Internet bubble, which is included in our sample period. Note also that these expectations are taken under the physical distribution. Hence, the association between risk neutral skewness and valuation ratios also relates to the analysis in the previous subsection pertaining to the relationship between risk neutral and physical probability distributions.

We use again measures of risk neutral higher moments constructed as in Section 2. As a valuation measure, we use the earnings-to-price ratio (henceforth $\mathrm{E} / \mathrm{P}$ ) of individual securities. ${ }^{13}$ We sort securities into decile portfolios based on risk neutral higher moment estimates, and then examine portfolio statistics. We present the results in Table 10. In the table, we report the average firm's volatility (in Panel A), skewness (in Panel B) and kurtosis (in Panel C) across each decile portfolio. For each portfolio, we also report the mean of three valuation ratios: FY0, the historical $\mathrm{E} / \mathrm{P}$ ratio, FY1, the next fiscal year forecast $\mathrm{E} / \mathrm{P}$ ratio, and FY2, the two years out forecasted $\mathrm{E} / \mathrm{P}$ ratio. ${ }^{14}$ As these results demonstrate, there are strong relations

\footnotetext{
${ }^{13}$ We use E/P ratios, rather than price-to-earnings, due to the prevalence of negative earnings for some firms in our sample. We do not exclude firms with negative earnings, since negative earnings are common during the Internet bubble, and it is precisely these firms for which higher moments may be more important in assessing valuation. Indeed, in our sample, firms with negative earnings per share tend to be smaller, more volatile and have higher betas; they also exhibit substantial differences in volatility, skewness and kurtosis.

${ }^{14}$ The historical E/P ratio is based on the month-end CRSP price per share and most recent Compustat earnings per share. Following Fama and French (1993), we assume that earnings per share data are available no more recently than six months after the fiscal year end. The forecast earnings per share are based on I/B/E/S mean estimates for the upcoming and following fiscal year ends.
} 
between risk-neutral moments and valuation ratios. Earnings-to-price ratios over all horizons decline as volatility and skewness increase; E/P ratios increase as kurtosis increases. Clearly, ex ante risk-neutral moments estimated from equity options are related to valuation ratios calculated for the underlying securities. In each case, the relation is sharpest for historical E/P measures, while the slope is most attenuated for FY2 forecasts, but the relations are there throughout. Intuitively, securities with higher volatility and higher skewness are more highly valued, i.e., they have lower E/P ratios. For the same level of expected earnings, investors are more willing to pay a higher price for securities which are more volatile, and more right-skewed. In a discounted cash-flow model, this higher valuation should come from lower discount rates, or higher expected growth rates. Conversely, securities which have higher kurtosis have higher E/P ratios, or are valued less highly.

We further divide the sample into two subperiods, using March of 2000 as the dividing point. If the pricing of technology stocks in the 1998-2000 period was related to higher moments, we should observe substantial differences in higher moments, or a significant increase in the sensitivity of valuation ratios to higher moments, in the first subperiod. While estimates of higher moments tend to be more extreme during the first subperiod (with the exception of volatility in one case), these differences are relatively small. Moreover, the relations between higher moments and valuation ratios are not more steeply sloped during this subperiod; in fact, if we estimate a linear relation between individual higher moments and E/P ratios for each subperiod, we find that for every E/P measure (historical, FY1 forecast and FY2 forecast), the relation between moments and E/P ratios tends to be more pronounced, or steeper, in the second subperiod, with the single exception of FY1 forecasts and volatility. Thus, while the results in this subsection indicate that valuation ratios and option-based risk-neutral higher moments are related, we find little support for the hypothesis that higher moments of individual firms' payoff distribution contributed significantly to higher valuations during the Internet bubble.

\section{Conclusions}

We explore the possibility that higher moments of the returns distribution are important in explaining security returns. Using a sample of option prices from 1996-2005, we estimate the moments of the risk-neutral density function for individual securities using the methodology of Bakshi, Kapadia, and Madan (2003). We analyze the relation between volatility, skewness and kurtosis and subsequent returns.

We find a strong relation between these moments and returns. Specifically, we find that 
high (low) volatility firms are associated with lower (higher) returns over the next month. This result is consistent with the results of Ang, Hodrick, Xing, and Zhang (2006). We also find that skewness has a strong negative relation with subsequent returns; firms with lower negative skewness, or positive skewness, earn lower returns. That is, investors seem to prefer positive skewness, and the returns differential associated with skewness is both economically and statistically significant. We also find a positive relation between kurtosis and returns. These relations are robust to controls for differences in firm characteristics, such as firm size, book-to-market ratios and betas, as well as liquidity and momentum. However, when we control for interactions between volatility, skewness and kurtosis, we find that the evidence for an independent relation between kurtosis and returns is relatively weak.

We use several different methods to control for differences in higher co-moments, and their related compensation for risk, when estimating the relation between higher moments and returns. These methods range from a simple single-factor data-generating process, suggested in Bakshi, Kapadia, and Madan (2003) and similar to the method (in physical returns) used in Harvey and Siddique (2000), to a non-parametric calculation of the stochastic discount factor. After controlling for higher co-moments, we continue to find evidence that idiosyncratic moments matter.

Finally, we examine the relation between risk neutral and physical skewness. Asset pricing models that consider the effects of skewness and fat tails in individual securities' distributions on expected returns deal with investors' estimates of the physical distribution. We therefore explore the relationship between the two probability measures to relate our empirical findings to the existing theoretical models. We find that $P$ and $Q$ skewness measures are strongly, but not perfectly, related. Risk neutral skewness is truly a market-based forward looking prediction-and the relation between risk-neutral moments and valuation ratios, for which we find evidence, is consistent with this interpretation. In contrast, the skewness un$\operatorname{der} P$ is historical in nature and backward looking by construction - which partly explains why the sorts under $Q$ and $P$ do not line up perfectly. The fact that there is an association between forward-looking, easy to compute skewness sorts under $Q$ and historical sorts under $P$, along with the fact that the mapping between the two measures is relatively stable over short horizons, leads us to believe that the results we obtain relate to existing theoretical asset pricing models. 


\section{References}

Ang, A., R.J. Hodrick, Y. Xing, and X. Zhang, 2006, The cross-section of volatility and expected returns, The Journal of Finance 61, 259-299.

— , 2009, High idiosyncratic volatility and low returns: International and further US evidence, Journal of Financial Economics 91, 1-23.

Bakshi, G., N. Kapadia, and D. Madan, 2003, Stock return characteristics, skew laws, and the differential pricing of individual equity options, Review of Financial Studies 16, 101.

Bakshi, G., and D. Madan, 2000, Spanning and derivative-security valuation, Journal of Financial Economics 55, 205-238.

Barberis, N., and M. Huang, 2008, Stocks as lotteries: The implications of probability weighting for security prices, The American Economic Review 98, 2066-2100.

Bates, D.S., 1991, The crash of '87: Was it expected? The evidence from options markets, Journal of Finance 46, 1009-1044.

Battalio, R., and P. Schultz, 2006, Options and the bubble, The Journal of Finance 61, 20712102.

BLANK, 2011, Ex ante skewness and expected stock returns - Supplementary material, Internet Appendix.

Bliss, R.R., and N. Panagirtzoglou, 2004, Option-Implied Risk Aversion Estimates, Journal of Finance 59, 411-446.

Bowley, A., 1920, Elements of Statistics (New York: Charles Scribner's Sons).

Boyer, B., T. Mitton, and K. Vorkink, 2010, Expected idiosyncratic skewness, Review of Financial Studies 23, 169-202.

Brunnermeier, M.K., C. Gollier, and J.A. Parker, 2007, Optimal beliefs, asset prices, and the preference for skewed returns, The American Economic Review 97, 159-165.

Chabi-Yo, F., E. Ghysels, and E. Renault, 2010, Factor asset pricing models implied by heterogeneous beliefs and attitudes towards risk, Working Paper - Ohio State Univeristy and UNC.

Chang, B.Y., P. Christoffersen, and K. Jacobs, 2009, Market skewness risk and the crosssection of stock returns, Working Paper, University of Toronto. 
Coval, J.D., and T. Shumway, 2001, Expected option returns, The Journal of Finance 56, 9831009.

Daniel, K., M. Grinblatt, S. Titman, and R. Wermers, 1997, Measuring mutual fund performance with characteristic-based benchmarks, Journal of Finance 52, 1035-1058.

Davis, J.L., E.F. Fama, and K.R. French, 2000, Characteristics, covariances, and average returns: 1929 to 1997, The Journal of Finance 55, 389-406.

Dennis, P., and S. Mayhew, 2002, Implied volatility skews: Evidence from options on individual securities, Journal of Financial and Quantitative Analysis 37, 471-493.

— , 2009, Risk-neutral skewness: Evidence from stock options, Journal of Financial and Quantitative Analysis 37, 471-493.

Dimson, E., 1979, Risk measurement when shares are subjected to infrequent trading, Journal of Financial Economics 7, 197-226.

Dittmar, R.F., 2002, Nonlinear pricing kernels, kurtosis preference, and evidence from the cross section of equity returns, The Journal of Finance 57, 369-403.

Fama, E.F., and K.R. French, 1993, Common risk factors in the returns on stocks and bonds, Journal of Financial Economics 33, 3-56.

Ghysels, E., A. Plazzi, and R. Valkanov, 2011, Conditional skewness of stock market returns in developed and emerging markets and its economic fundamentals, Paper available at http://papers.ssrn.com/sol3/papers.cfm?abstract_id=1761446.

Green, T.C., and B.H. Hwang, 2009, Ipos as lotteries: Expected skewness and first-day returns, Working paper, Emory University-Goizueta Business School.

Harvey, C.R., and A. Siddique, 2000, Conditional skewness in asset pricing tests, The Journal of Finance 55, 1263-1295.

Harvey, Campbell R., and Akhtar Siddique, 1999, Autoregressive Conditional Skewness, Journal of Financial and Quantitative Analysis 34, 465-487.

Hinkley, D.V., 1975, On Power Transformations to Symmetry, Biometrika 62, 101-111.

Jackwerth, J.C., and M. Rubinstein, 1996, Recovering probability distributions from option prices, Journal of Finance 51, 1611-1631.

Kim, Tae-Hwan, and Halbert White, 2004, On More Robust Estimation of Skewness and Kurtosis, Finance Research Letters 1, 56-70. 
Kraus, A., and R.H. Litzenberger, 1976, Skewness preference and the valuation of risk assets, Journal of Finance 31, 1085-1100.

Kraus, A., and R. Litzenberger, 1983, On the distributional conditions for a consumptionoriented three moment CAPM, Journal of Finance 38, 1381-1391.

Mitton, T., and K. Vorkink, 2007, Equilibrium underdiversification and the preference for skewness, Review of Financial Studies 20, 1255-1288.

Ofek, E., and M. Richardson, 2003, DotCom mania: The rise and fall of internet stock prices, The Journal of Finance 58, 1113-1138.

Pástor, L., and R.F. Stambaugh, 2003, Liquidity risk and expected stock returns, Journal of Political Economy 111, 642-685.

Pearson, Karl, 1895, Contributions to the Mathematical Theory of Evolution. II. Skew Variation in Homogeneous Material, Philosophical Transactions of the Royal Society of London. A 186, 343-414.

Rubinstein, M.E., 1973, The fundamental theorem of parameter-preference security valuation, Journal of Financial and Quantitative Analysis 8, 61-69.

— , 1994, Implied binomial trees, Journal of Finance 49, 771-818.

Shleifer, A., and R.W. Vishny, 1997, The limits of arbitrage, Journal of Finance 52, 35-55.

White, Halbert, Tae-Hwan Kim, and Simone Manganelli, 2008, Modeling Autoregressive Conditional Skewness and Kurtosis with Multi-Quantile CAViaR, in Robert F. Engle, and Halbert White, ed.: A Festschrift in Honor of Clive W.J. Granger. Oxford University Press.

Xing, Y., X. Zhang, and R. Zhao, 2010, What Does the Individual Option Volatility Smirk Tell Us About Future Equity Returns?, Journal of Financial and Quantitative Analysis 45, 641-662.

Zhang, Y., 2006, Individual skewness and the cross-section of average stock returns, Unpublished paper, Yale University. 


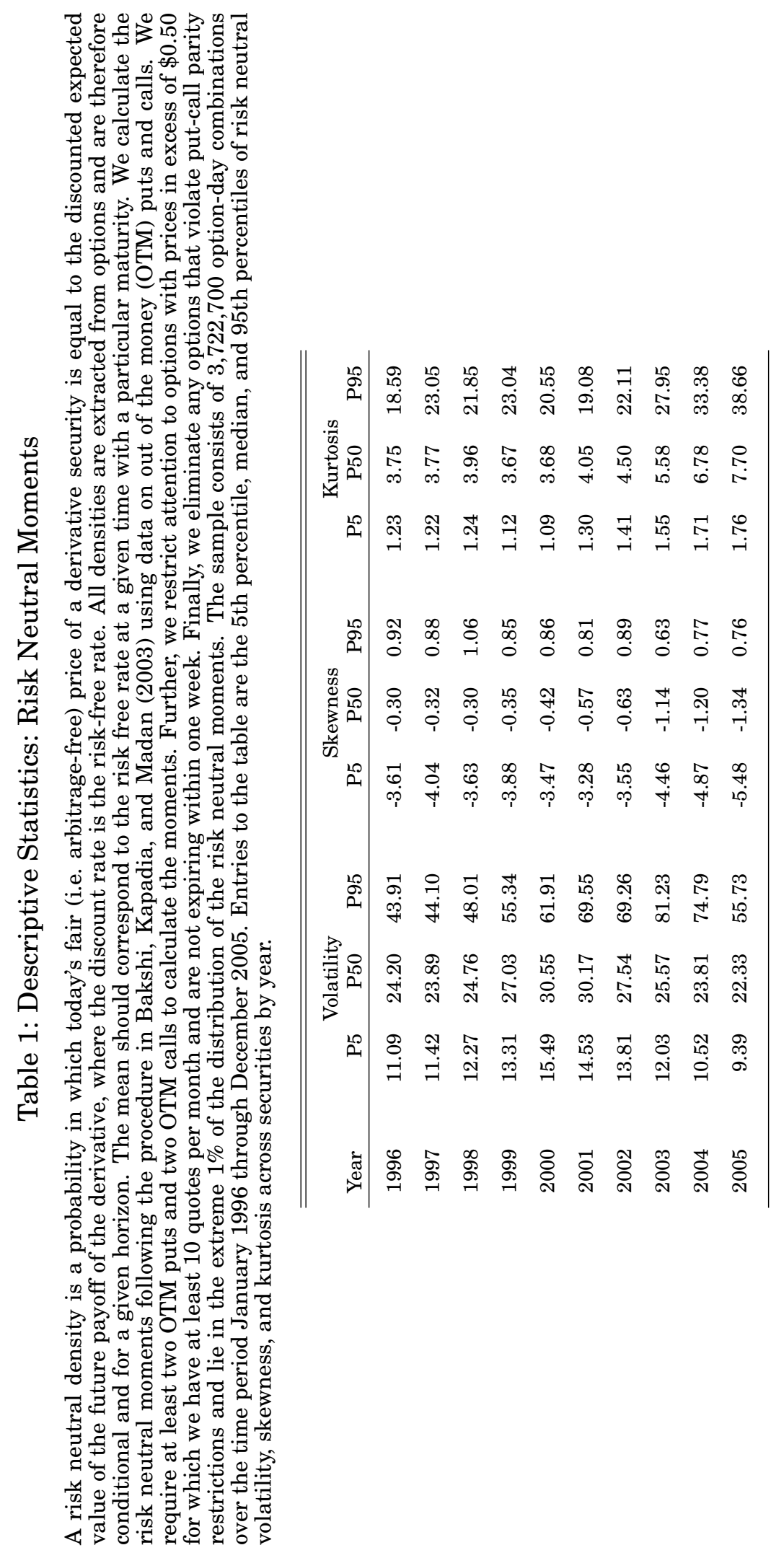




\section{Table 2: Descriptive Statistics: Risk Neutral Moment Portfolios}

Panels A and B present summary statistics for portfolios sorted on measures of firms' risk-neutral moments. Firms are sorted on average risk-neutral volatility, skewness, and kurtosis within each calendar quarter into terciles based on $30^{\text {th }}$ and $70^{\text {th }}$ percentiles. We then form equally-weighted portfolios of these firms, holding the moment ranking constant for the subsequent calendar quarter. Risk-neutral moments are calculated using the procedure in Bakshi, Kapadia, and Madan (2003); in Panel A we report results using options closest to three months to maturity, and in Panel B results with options closest to twelve months to maturity. The first column of each panel presents mean monthly returns. The second column presents characteristic-adjusted returns, calculated by determining, for each firm, the Fama-French 5X5 size- and book-to-market portfolio to which it belongs and subtracting that return. The next three columns present the average individual firm's risk-neutral volatility, skewness and kurtosis of the stocks in the portfolio for the portfolio formation period. The final three columns display the beta, log market value and book-to-market equity ratio of the portfolio. The final row of the table presents $t$ statistics of the null hypothesis that the difference in the third and first tercile are zero. Monthly return data cover the period 4/96 through 12/05, for a total of 117 monthly observations.

Panel A: 3 Months to Maturity

Volatility

\begin{tabular}{lrrrrrrrr}
\hline \hline & Mean & Char-Adj & & & & & & \\
Tercile & Return & Return & Vol & Skew & Kurt & Beta & ln MV & B/M \\
\hline 1 & 1.354 & 0.441 & 17.837 & -1.284 & 10.764 & 0.916 & 15.739 & 0.349 \\
2 & 0.987 & 0.088 & 28.513 & -1.151 & 9.521 & 1.354 & 14.701 & 0.342 \\
3 & 0.792 & 0.081 & 49.816 & -1.273 & 6.453 & 1.873 & 14.114 & 0.370 \\
$3-1$ & -0.562 & -0.360 & 31.979 & 0.011 & -4.312 & 0.957 & -1.625 & 0.020 \\
$\mathrm{t}(3-1)$ & -0.713 & -0.571 & 44.376 & 0.151 & -5.220 & 27.246 & -21.999 & 2.284 \\
\hline
\end{tabular}

Skewness

\begin{tabular}{lrrrrrrrr}
\multicolumn{7}{c}{ Skewness } \\
\hline \hline & Mean & Char-Adj & & & & & & \\
Tercile & Return & Return & Vol & Skew & Kurt & Beta & ln MV & B/M \\
\hline 1 & 1.448 & 0.570 & 31.507 & -2.814 & 15.437 & 1.246 & 15.636 & 0.331 \\
2 & 1.042 & 0.205 & 32.261 & -0.980 & 5.392 & 1.420 & 14.741 & 0.357 \\
3 & 0.627 & -0.216 & 31.140 & 0.026 & 7.327 & 1.408 & 14.170 & 0.370 \\
$3-1$ & -0.821 & -0.786 & -0.367 & 2.841 & -8.110 & 0.162 & -1.466 & 0.039 \\
$\mathrm{t}(3-1)$ & -2.062 & -2.079 & -0.633 & 33.671 & -6.456 & 5.627 & -31.693 & 5.908 \\
\hline
\end{tabular}

\begin{tabular}{lrrrrrrrr}
\multicolumn{7}{c}{ Kurtosis } \\
\hline \hline & Mean & Char-Adj & & & & & & \\
Tercile & Return & Return & Vol & Skew & Kurt & Beta & ln MV & B/M \\
\hline 1 & 0.631 & -0.247 & 37.250 & -0.369 & 2.370 & 1.523 & 13.996 & 0.388 \\
2 & 1.106 & 0.308 & 31.710 & -0.955 & 5.449 & 1.386 & 14.770 & 0.351 \\
3 & 1.355 & 0.458 & 26.134 & -2.450 & 20.302 & 1.177 & 15.766 & 0.322 \\
$3-1$ & 0.724 & 0.705 & -11.116 & -2.081 & 17.933 & -0.346 & 1.770 & -0.066 \\
$\mathrm{t}(3-1)$ & 2.011 & 2.119 & -26.365 & -24.244 & 14.378 & -10.839 & 45.560 & -8.732 \\
\hline
\end{tabular}

Table continued on next page... 
Panel B: 12 Months to Maturity Volatility

\begin{tabular}{rrrrrrrrr}
\hline \hline & Mean & Char-Adj & & & & & & \\
Tercile & Return & Return & Vol & Skew & Kurt & Beta & ln MV & B/M \\
\hline 1 & 1.338 & 0.441 & 17.488 & -1.295 & 10.908 & 0.897 & 15.846 & 0.350 \\
2 & 1.014 & 0.142 & 27.870 & -1.115 & 9.316 & 1.355 & 14.686 & 0.340 \\
3 & 0.772 & 0.004 & 47.956 & -1.238 & 6.469 & 1.896 & 14.028 & 0.373 \\
$3-1$ & -0.566 & -0.437 & 30.468 & 0.057 & -4.439 & 0.998 & -1.819 & 0.023 \\
$\mathrm{t}(3-1)$ & -0.694 & -0.679 & 50.135 & 0.789 & -5.374 & 27.299 & -26.073 & 2.375 \\
\hline
\end{tabular}

Skewness

\begin{tabular}{rrrrrrrrr}
\hline \hline & Mean & Char-Adj & & & & & & \\
Tercile & Return & Return & Vol & Skew & Kurt & Beta & ln MV & B/M \\
\hline 1 & 1.446 & 0.548 & 30.156 & -2.743 & 15.207 & 1.261 & 15.591 & 0.330 \\
2 & 0.979 & 0.153 & 31.313 & -0.974 & 5.480 & 1.414 & 14.754 & 0.355 \\
3 & 0.714 & -0.123 & 30.689 & 0.019 & 7.323 & 1.400 & 14.197 & 0.373 \\
$3-1$ & -0.732 & -0.671 & 0.533 & 2.761 & -7.884 & 0.140 & -1.394 & 0.043 \\
$\mathrm{t}(3-1)$ & -1.864 & -1.783 & 1.073 & 31.855 & -6.286 & 5.085 & -31.502 & 6.601 \\
\hline
\end{tabular}

Kurtosis

\begin{tabular}{rrrrrrrrr}
\hline \hline & Mean & Char-Adj & & & & & & \\
Tercile & Return & Return & Vol & Skew & Kurt & Beta & ln MV & B/M \\
\hline 1 & 0.622 & -0.223 & 36.600 & -0.371 & 2.408 & 1.512 & 13.998 & 0.390 \\
2 & 1.127 & 0.295 & 30.441 & -0.951 & 5.533 & 1.387 & 14.782 & 0.352 \\
3 & 1.337 & 0.459 & 25.416 & -2.382 & 20.036 & 1.188 & 15.747 & 0.318 \\
$3-1$ & 0.715 & 0.682 & -11.184 & -2.010 & 17.627 & -0.324 & 1.749 & -0.072 \\
$\mathrm{t}(3-1)$ & 2.055 & 2.120 & -25.670 & -23.057 & 14.085 & -11.175 & 41.433 & -9.975 \\
\hline
\end{tabular}




\section{Table 3: Risk Neutral Moment Double- and Triple-Sorted Portfolios}

The table presents the results of multi-way sorts on risk neutral moments. We independently sort firms into tercile portfolios based on volatility, skewness, and kurtosis, and then form portfolios on the intersection of volatility and either skewness or kurtosis. For each of the nine portfolios formed, we report the average of subsequent returns. The results from sorting on volatility and skewness, for three-month and twelve-month options, are reported in Panel A, the results from sorting on volatility and kurtosis are reported in Panel B. We present results from sorting on medians of volatility, skewness, and kurtosis independently in Panel C. In panels A and B, the number of firms in each portfolio are reported in parentheses below the returns.

Panel A: Volatility-Skewness Sorts

\begin{tabular}{lccc}
\multicolumn{4}{c}{3 Months to Maturity } \\
\hline \hline & S1 & S2 & S3 \\
\hline V1 & 1.409 & 1.420 & 1.048 \\
N & $(52)$ & $(39)$ & $(32)$ \\
V2 & 1.044 & 0.902 & 0.765 \\
N & $(33)$ & $(25)$ & $(34)$ \\
V3 & 1.374 & 0.650 & 0.369 \\
N & $(37)$ & $(28)$ & $(27)$ \\
\hline
\end{tabular}

\begin{tabular}{lccc}
\multicolumn{4}{c}{ 12 Months to Maturity } \\
\hline \hline & S1 & S2 & S3 \\
\hline V1 & 1.351 & 1.288 & 1.005 \\
N & $(53)$ & $(39)$ & $(31)$ \\
V2 & 1.132 & 0.949 & 0.944 \\
N & $(34)$ & $(25)$ & $(33)$ \\
V3 & 1.376 & 0.419 & 0.453 \\
N & $(36)$ & $(28)$ & $(28)$ \\
\hline
\end{tabular}

Panel B: Volatility-Kurtosis Sorts

\begin{tabular}{lccc}
\multicolumn{4}{c}{ 3 Months to Maturity } \\
\hline \hline & K1 & K2 & K3 \\
\hline V1 & 1.144 & 1.346 & 1.438 \\
N & $(34)$ & $(37)$ & $(52)$ \\
V2 & 1.190 & 0.513 & 0.946 \\
N & $(37)$ & $(29)$ & $(26)$ \\
V3 & 0.349 & 1.409 & 1.213 \\
N & $(51)$ & $(27)$ & $(14)$ \\
\hline
\end{tabular}

\begin{tabular}{lccc}
\multicolumn{4}{c}{ 12 Months to Maturity } \\
\hline \hline & K1 & K2 & K3 \\
\hline V1 & 0.963 & 1.325 & 1.366 \\
N & $(33)$ & $(38)$ & $(52)$ \\
V2 & 1.211 & 0.683 & 1.254 \\
N & $(37)$ & $(29)$ & $(26)$ \\
V3 & 0.377 & 1.530 & 0.829 \\
N & $(52)$ & $(26)$ & $(14)$ \\
\hline
\end{tabular}

Panel C: Volatility-Skewness-Kurtosis Sorts

3 Months to Maturity

\begin{tabular}{lcccccccc}
\hline \hline & V1S1K1 & V1S1K2 & V1S2K1 & V1S2K2 & V2S1K1 & V2S1K2 & V2S2K1 & V2S2K2 \\
\hline Mean & 1.623 & 1.304 & 1.087 & 1.002 & 1.250 & 1.196 & 0.592 & 0.872 \\
$\mathrm{~N}$ & $(8)$ & $(71)$ & $(52)$ & $(22)$ & $(25)$ & $(49)$ & $(68)$ & $(11)$ \\
\hline \multicolumn{7}{c}{12 Months to Maturity } \\
\hline \hline \\
\hline \multirow{8}{*}{ Mean } & V1S1K1 & V1S1K2 & V1S2K1 & V1S2K2 & V2S1K1 & V2S1K2 & V2S2K1 & V2S2K2 \\
$\mathrm{N}$ & 1.424 & 1.209 & 1.110 & 1.069 & 1.301 & 1.268 & 0.621 & 0.626 \\
& $(9)$ & $(72)$ & $(51)$ & $(22)$ & $(24)$ & $(48)$ & $(70)$ & $(12)$ \\
\hline
\end{tabular}




\section{Table 4: Fama-French Factor Risk Adjustment: Risk Neutral Moment-Sorted Portfolios}

The table presents the results of time series regressions of excess return differentials (High-Low) between portfolios ranked on risk neutral volatility, skewness, and kurtosis on the three Fama and French (1993) factors MRP (the return on the value-weighted market portfolio in excess of a one-month T-Bill), SMB (the difference in returns on a portfolio of small capitalization and large capitalization stocks), and HML (the difference in returns on a portfolio of high and low book equity to market equity stocks). The moment-sorted portfolios are equally-weighted, formed on the basis of terciles and re-formed each quarter. The table presents point estimates of the coefficients and t-statistics. In Panel $\mathrm{A}$, we use options closest to 3 months to maturity to calculate risk neutral moments; 12 month options are used in Panel B. Data cover the period April 1996 through December 2005 for 117 monthly observations.

Panel A: 3 Months to Maturity

\begin{tabular}{|c|c|c|c|c|c|}
\hline \multicolumn{6}{|c|}{ Volatility } \\
\hline$\overline{\overline{\text { Rank }}}$ & $\overline{\alpha \alpha}$ & $\overline{\beta_{M R P}}$ & $\overline{\beta_{S M B}}$ & $\overline{\overline{\beta_{H M L}}}$ & Adj. $R^{2}$ \\
\hline 1 & $\begin{array}{l}0.648 \\
3.337\end{array}$ & $\begin{array}{r}0.762 \\
17.817\end{array}$ & $\begin{array}{l}-0.448 \\
-9.652\end{array}$ & $\begin{array}{l}-0.240 \\
-4.340\end{array}$ & 0.835 \\
\hline 2 & $\begin{array}{l}0.465 \\
1.652\end{array}$ & $\begin{array}{r}0.977 \\
15.750\end{array}$ & $\begin{array}{l}-0.383 \\
-5.684\end{array}$ & $\begin{array}{r}-0.803 \\
-10.010\end{array}$ & 0.877 \\
\hline 3 & $\begin{array}{l}0.170 \\
0.414\end{array}$ & $\begin{array}{r}1.313 \\
14.551\end{array}$ & $\begin{array}{l}-0.230 \\
-2.351\end{array}$ & $\begin{array}{r}-1.183 \\
-10.149\end{array}$ & 0.880 \\
\hline $3-1$ & $\begin{array}{l}-0.478 \\
-1.109\end{array}$ & $\begin{array}{l}0.550 \\
5.786\end{array}$ & $\begin{array}{l}0.218 \\
2.113\end{array}$ & $\begin{array}{l}-0.943 \\
-7.674\end{array}$ & 0.748 \\
\hline \multicolumn{6}{|c|}{ Skewness } \\
\hline $\begin{array}{ll}\text { Rank } \\
1\end{array}$ & $\begin{array}{r}\alpha \\
0.975 \\
2.630\end{array}$ & $\begin{array}{r}\beta_{M R P} \\
0.831 \\
10.173\end{array}$ & $\begin{array}{c}\beta_{S M B} \\
-0.240 \\
-2.709\end{array}$ & $\begin{array}{c}\beta_{H M L} \\
-0.743 \\
-7.042\end{array}$ & $\begin{array}{r}\text { Adj. } R^{2} \\
0.770\end{array}$ \\
\hline 2 & $\begin{array}{l}0.445 \\
1.911\end{array}$ & $\begin{array}{r}1.029 \\
20.057\end{array}$ & $\begin{array}{l}-0.368 \\
-6.614\end{array}$ & $\begin{array}{r}-0.777 \\
-11.716\end{array}$ & 0.917 \\
\hline 3 & $\begin{array}{l}-0.126 \\
-0.455\end{array}$ & $\begin{array}{r}1.175 \\
19.314\end{array}$ & $\begin{array}{l}-0.459 \\
-6.946\end{array}$ & $\begin{array}{l}-0.716 \\
-9.110\end{array}$ & 0.896 \\
\hline $3-1$ & $\begin{array}{l}-1.100 \\
-2.717\end{array}$ & $\begin{array}{l}0.344 \\
3.855\end{array}$ & $\begin{array}{l}-0.219 \\
-2.255\end{array}$ & $\begin{array}{l}0.027 \\
0.235\end{array}$ & 0.129 \\
\hline \multicolumn{6}{|c|}{ Kurtosis } \\
\hline $\begin{array}{l}\text { Rank } \\
1\end{array}$ & $\begin{array}{r}\alpha \\
-0.223 \\
-0.804\end{array}$ & $\begin{array}{r}\beta_{M R P} \\
1.237 \\
20.211\end{array}$ & $\begin{array}{c}\beta_{S M B} \\
-0.358 \\
-5.392\end{array}$ & $\begin{array}{c}\beta_{H M L} \\
-0.709 \\
-8.965\end{array}$ & $\begin{array}{r}\text { Adj. } R^{2} \\
0.905\end{array}$ \\
\hline 2 & $\begin{array}{l}0.524 \\
2.210\end{array}$ & $\begin{array}{r}1.021 \\
19.554\end{array}$ & $\begin{array}{l}-0.395 \\
-6.961\end{array}$ & $\begin{array}{r}-0.775 \\
-11.477\end{array}$ & 0.912 \\
\hline 3 & $\begin{array}{l}0.961 \\
2.916\end{array}$ & $\begin{array}{r}0.780 \\
10.741\end{array}$ & $\begin{array}{l}-0.304 \\
-3.863\end{array}$ & $\begin{array}{l}-0.752 \\
-8.018\end{array}$ & 0.792 \\
\hline $3-1$ & $\begin{array}{l}1.184 \\
3.677\end{array}$ & $\begin{array}{l}-0.457 \\
-6.441\end{array}$ & $\begin{array}{l}0.054 \\
0.698\end{array}$ & $\begin{array}{l}-0.043 \\
-0.472\end{array}$ & 0.327 \\
\hline
\end{tabular}

Table continued on next page ... 
Panel B: 12 Months to Maturity

\begin{tabular}{lrrrrr}
\hline \hline Rank & $\alpha$ & $\beta_{M R P}$ & $\beta_{S M B}$ & $\beta_{H M L}$ & Adj. $R^{2}$ \\
\hline 1 & 0.666 & 0.734 & -0.453 & -0.246 & 0.829 \\
& 3.460 & 17.306 & -9.828 & -4.495 & \\
2 & 0.500 & 0.971 & -0.384 & -0.806 & 0.878 \\
& 1.788 & 15.746 & -5.737 & -10.110 & \\
3 & 0.104 & 1.350 & -0.224 & -1.173 & 0.877 \\
& 0.247 & 14.551 & -2.229 & -9.785 & \\
$3-1$ & -0.562 & 0.615 & 0.228 & -0.926 & 0.749 \\
& -1.262 & 6.264 & 2.141 & -7.298 & \\
\hline \multirow{5}{*}{ Skewness } & & \\
\hline \hline Rank & $\alpha$ & $\beta_{M R P}$ & $\beta_{S M B}$ & $\beta_{H M L}$ & Adj. $R^{2}$ \\
\hline 1 & 0.975 & 0.829 & -0.232 & -0.747 & 0.771 \\
& 2.630 & 10.146 & -2.612 & -7.076 & \\
2 & 0.396 & 1.035 & -0.380 & -0.798 & 0.914 \\
& 1.657 & 19.642 & -6.649 & -11.720 & \\
3 & -0.059 & 1.169 & -0.451 & -0.684 & 0.901 \\
& -0.224 & 20.065 & -7.135 & -9.087 & \\
$3-1$ & -1.034 & 0.341 & -0.220 & 0.063 & 0.124 \\
& -2.579 & 3.854 & -2.292 & 0.549 & \\
\hline
\end{tabular}

\begin{tabular}{lrrrrr}
\multicolumn{6}{c}{ Kurtosis } \\
\hline \hline Rank & $\alpha$ & $\beta_{M R P}$ & $\beta_{S M B}$ & $\beta_{H M L}$ & Adj. $R^{2}$ \\
\hline 1 & -0.246 & 1.231 & -0.354 & -0.684 & 0.906 \\
& -0.908 & 20.585 & -5.459 & -8.853 & \\
2 & 0.572 & 1.011 & -0.382 & -0.804 & 0.909 \\
& 2.347 & 18.830 & -6.554 & -11.582 & \\
3 & 0.921 & 0.800 & -0.326 & -0.739 & 0.799 \\
& 2.853 & 11.246 & -4.217 & -8.037 & \\
$3-1$ & 1.167 & -0.431 & 0.029 & -0.054 & 0.309 \\
& 3.699 & -6.202 & 0.382 & -0.605 & \\
\hline
\end{tabular}




\section{Table 5: Descriptive Statistics: Risk Neutral Co-moment Portfolios}

Panels A and B present summary statistics for portfolios sorted on measures of firms' risk-neutral moments. Firms are sorted on average risk-neutral covariance, co-skewness, and co-kurtosis within each calendar quarter into terciles based on $30^{\text {th }}$ and $70^{\text {th }}$ percentiles. We then form equally-weighted portfolios of these firms, holding the moment ranking constant for the subsequent calendar quarter. The co-moments are calculated using firm risk-neutral moments and risk-neutral moments on the S\&P 500 index. Specifically, we calculate the co-moments as

$$
\begin{aligned}
\operatorname{COVAR} R_{i}^{Q} & =\frac{S_{i, t}}{C_{i, t}} \mathcal{N}\left(\frac{\ln \left(S_{i, t} / K_{i}\right)+\left(r-\delta+0.5 \sigma^{2}\right) \tau}{\sigma \sqrt{\tau}}\right) \beta_{i}=b_{i} \\
\operatorname{COSKEW_{i}^{Q}} & =b_{i} S K E W_{m, t}^{Q}(\tau) \frac{V A R_{i, t}^{Q}(\tau)}{\sqrt{V A R_{m, t}^{Q}(, \tau)}} \\
C O K U R T_{i}^{Q} & =b_{i} \frac{K U R T_{m, t}^{Q}(\tau)}{V A R_{i, t}^{Q}(\tau) V A R_{m, t}^{Q}(, \tau)}
\end{aligned}
$$

In these expressions, $S_{i, t}$ is the stock price on date $t, C_{i, t}$ is the call price, $K_{i}$ is the strike price, $r$ is the risk-free rate, $\delta$ is the dividend yield, and $\beta_{i}$ is the Dimson beta calculated over the past 250 trading days. The subscript $m$ refers to the S\&P 500 index. Risk-neutral moments are calculated using the procedure in Bakshi, Kapadia, and Madan (2003); in Panel A we report results using options closest to three months to maturity, and in Panel B results with options closest to twelve months to maturity. The first column of each panel presents mean monthly returns. The second column presents characteristic-adjusted returns, calculated by determining, for each firm, the Fama-French 5X5 size- and book-to-market portfolio to which it belongs and subtracting that return. The next three columns present the average risk-neutral volatility, skewness and kurtosis of the stocks in the portfolio for the portfolio formation period. The final three columns display the beta, log market value and book-to-market equity ratio of the portfolio. Monthly return data cover the period 4/96 through 12/05, for a total of 117 monthly observations.

\begin{tabular}{|c|c|c|c|c|c|c|c|c|}
\hline Tercile & $\begin{array}{r}\text { Mean } \\
\text { Return }\end{array}$ & $\begin{array}{l}\text { Char-Adj } \\
\text { Return }\end{array}$ & Vol & Skew & Kurt & Beta & $\ln \mathrm{MV}$ & $\mathrm{B} / \mathrm{M}$ \\
\hline 1 & 0.839 & 0.078 & 31.505 & -0.879 & 10.309 & 1.511 & 14.457 & 0.313 \\
\hline 2 & 0.913 & 0.155 & 31.159 & -1.057 & 6.912 & 1.410 & 14.730 & 0.337 \\
\hline 3 & 1.253 & 0.215 & 32.653 & -1.845 & 9.728 & 1.224 & 15.642 & 0.382 \\
\hline $3-1$ & 0.414 & 0.137 & 1.148 & -0.966 & -0.581 & -0.286 & 1.185 & 0.069 \\
\hline $\mathrm{t}(3-1)$ & 0.812 & 0.323 & 1.337 & -13.639 & -0.590 & -9.487 & 12.030 & 8.227 \\
\hline \multicolumn{9}{|c|}{ Coskewness } \\
\hline Tercile & $\begin{array}{r}\text { Mean } \\
\text { Return }\end{array}$ & $\begin{array}{l}\text { Char-Adj } \\
\text { Return }\end{array}$ & Vol & Skew & Kurt & Beta & $\ln \mathrm{MV}$ & $\mathrm{B} / \mathrm{M}$ \\
\hline 1 & 1.164 & 0.116 & 26.782 & -1.780 & 10.119 & 1.068 & 15.790 & 0.366 \\
\hline 2 & 1.093 & 0.327 & 32.797 & -1.120 & 7.021 & 1.459 & 14.717 & 0.346 \\
\hline 3 & 0.682 & -0.040 & 35.171 & -0.860 & 9.755 & 1.614 & 14.323 & 0.318 \\
\hline $3-1$ & -0.482 & -0.156 & 8.389 & 0.920 & -0.365 & 0.545 & -1.467 & -0.048 \\
\hline $\mathrm{t}(3-1)$ & -0.791 & -0.316 & 17.027 & 13.524 & -0.376 & 22.463 & -14.957 & -6.440 \\
\hline \multicolumn{9}{|c|}{ Cokurtosis } \\
\hline & $\overline{\text { Mean }}$ & Char-Adj & & & & & & \\
\hline Tercile & Return & Return & Vol & Skew & Kurt & Beta & $\ln \mathrm{MV}$ & $\mathrm{B} / \mathrm{M}$ \\
\hline 1 & 0.732 & 0.006 & 39.428 & -0.870 & 9.224 & 1.725 & 14.224 & 0.324 \\
\hline 2 & 0.966 & 0.177 & 32.620 & -1.146 & 7.139 & 1.445 & 14.730 & 0.342 \\
\hline 3 & 1.284 & 0.260 & 22.779 & -1.734 & 10.505 & 0.985 & 15.867 & 0.365 \\
\hline $3-1$ & 0.552 & 0.254 & -16.650 & -0.864 & 1.281 & -0.740 & 1.643 & 0.042 \\
\hline $\mathrm{t}(3-1)$ & 0.802 & 0.459 & -49.652 & -13.349 & 1.316 & -27.949 & 17.534 & 5.260 \\
\hline
\end{tabular}

Panel A: 3 Months to Maturity

Covariance

Table continued on next page... 
Panel B: 12 Months to Maturity Covariance

\begin{tabular}{|c|c|c|c|c|c|c|c|c|}
\hline Tercile & $\begin{array}{r}\text { Mean } \\
\text { Return }\end{array}$ & $\begin{array}{r}\text { Char-Adj } \\
\text { Return }\end{array}$ & Vol & Skew & Kurt & Beta & $\ln \mathrm{MV}$ & $\mathrm{B} / \mathrm{M}$ \\
\hline 1 & 0.682 & -0.063 & 32.871 & -0.792 & 9.584 & 1.640 & 14.265 & 0.303 \\
\hline 2 & 0.972 & 0.206 & 30.316 & -1.057 & 6.952 & 1.438 & 14.693 & 0.341 \\
\hline 3 & 1.332 & 0.294 & 28.948 & -1.850 & 10.276 & 1.077 & 15.875 & 0.387 \\
\hline $3-1$ & 0.649 & 0.357 & -3.924 & -1.058 & 0.692 & -0.563 & 1.610 & 0.084 \\
\hline $\mathrm{t}(3-1)$ & 0.950 & 0.668 & -4.849 & -15.490 & 0.708 & -24.419 & 18.416 & 13.706 \\
\hline \multicolumn{9}{|c|}{ Coskewness } \\
\hline Tercile & $\begin{array}{r}\text { Mean } \\
\text { Return }\end{array}$ & $\begin{array}{r}\text { Char-Adj } \\
\text { Return }\end{array}$ & Vol & Skew & Kurt & Beta & $\ln \mathrm{MV}$ & $\mathrm{B} / \mathrm{M}$ \\
\hline 1 & 1.281 & 0.249 & 25.814 & -1.834 & 10.563 & 0.992 & 15.955 & 0.378 \\
\hline 2 & 1.039 & 0.220 & 31.240 & -1.082 & 6.999 & 1.465 & 14.701 & 0.341 \\
\hline 3 & 0.641 & -0.043 & 34.754 & -0.777 & 9.220 & 1.702 & 14.174 & 0.311 \\
\hline $3-1$ & -0.640 & -0.291 & 8.940 & 1.058 & -1.343 & 0.710 & -1.781 & -0.068 \\
\hline $\mathrm{t}(3-1)$ & -0.867 & -0.506 & 14.338 & 15.602 & -1.391 & 33.332 & -20.626 & -10.138 \\
\hline \multicolumn{9}{|c|}{ Cokurtosis } \\
\hline Tercile & $\begin{array}{r}\text { Mean } \\
\text { Return }\end{array}$ & $\begin{array}{r}\text { Char-Adj } \\
\text { Return }\end{array}$ & Vol & Skew & Kurt & Beta & $\ln \mathrm{MV}$ & $\mathrm{B} / \mathrm{M}$ \\
\hline 1 & 0.753 & 0.027 & 36.878 & -0.789 & 9.043 & 1.776 & 14.133 & 0.314 \\
\hline 2 & 0.943 & 0.137 & 31.516 & -1.104 & 6.950 & 1.449 & 14.687 & 0.344 \\
\hline 3 & 1.296 & 0.281 & 23.339 & -1.789 & 10.817 & 0.944 & 16.012 & 0.372 \\
\hline $3-1$ & 0.543 & 0.254 & -13.538 & -1.000 & 1.773 & -0.832 & 1.878 & 0.058 \\
\hline$t(3-1)$ & 0.714 & 0.431 & -35.948 & -15.145 & 1.786 & -30.623 & 22.235 & 7.796 \\
\hline
\end{tabular}




\section{Table 6: Fama-French Factor Risk Adjustment: Risk Neutral Co-moment-Sorted Portfolios}

The table presents the results of time series regressions of excess return differentials (High-Low) between portfolios ranked on risk neutral covariance, co-skewness, and co-kurtosis on the three Fama and French (1993) factors MRP (the return on the value-weighted market portfolio in excess of a one-month T-Bill), SMB (the difference in returns on a portfolio of small capitalization and large capitalization stocks), and HML (the difference in returns on a portfolio of high and low book equity to market equity stocks). The co-moments are calculated using firm risk-neutral moments and risk-neutral moments on the S\&P 500 index. Specifically, we calculate the co-moments as

$$
\begin{aligned}
\operatorname{COVAR} R_{i}^{Q} & =\frac{S_{i, t}}{C_{i, t}} \mathcal{N}\left(\frac{\ln \left(S_{i, t} / K_{i}\right)+\left(r-\delta+0.5 \sigma^{2}\right) \tau}{\sigma \sqrt{\tau}}\right) \beta_{i}=b_{i} \\
\operatorname{COSKEW_{i}^{Q}} & =b_{i} S K E W_{m, t}^{Q}(\tau) \frac{V A R_{i, t}^{Q}(\tau)}{\sqrt{V A R_{m, t}^{Q}(, \tau)}} \\
C O K U R T_{i}^{Q} & =b_{i} \frac{K U R T_{m, t}^{Q}(\tau)}{V A R_{i, t}^{Q}(\tau) V A R_{m, t}^{Q}(, \tau)}
\end{aligned}
$$

In these expresssions, $S_{i, t}$ is the stock price on date $t, C_{i, t}$ is the call price, $K_{i}$ is the strike price, $r$ is the risk-free rate, $\delta$ is the dividend yield, and $\beta_{i}$ is the Dimson beta calculated over the past 250 trading days. The subscript $m$ refers to the S\&P 500 index. The moment-sorted portfolios are equally-weighted, formed on the basis of terciles and re-formed each quarter. The table presents point estimates of the coefficients and t-statistics. In Panel A, we use options closest to 3 months to maturity to calculate risk neutral moments; 12 month options are used in Panel B. Data cover the period April 1996 through December 2005 for 117 monthly observations.

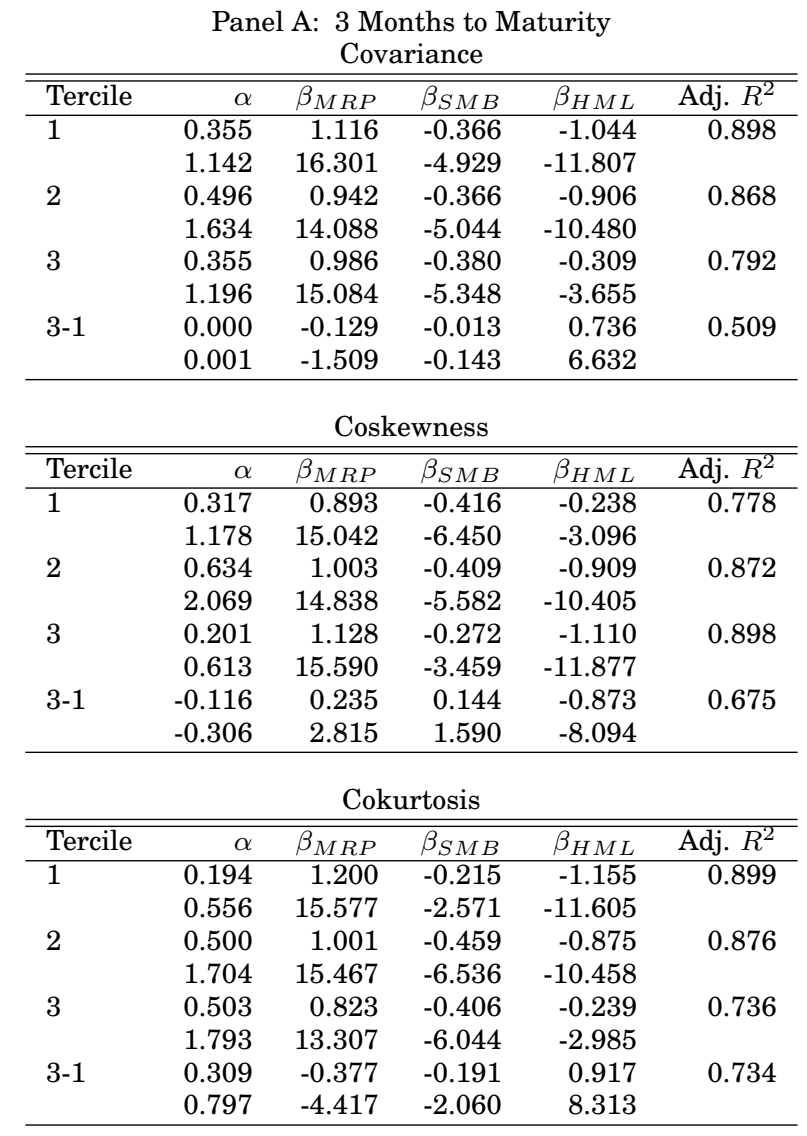

Table continued on next page. 
Panel B: 12 Months to Maturity

\begin{tabular}{lrrrrr}
\multicolumn{6}{c}{ Covariance } \\
\hline \hline Tercile & $\alpha$ & $\beta_{M R P}$ & $\beta_{S M B}$ & $\beta_{H M L}$ & Adj. $R^{2}$ \\
\hline 1 & 0.332 & 1.127 & -0.354 & -1.246 & 0.880 \\
& 0.890 & 13.693 & -3.968 & -11.718 & \\
2 & 0.500 & 0.964 & -0.295 & -0.895 & 0.861 \\
& 1.562 & 13.672 & -3.859 & -9.819 & \\
3 & 0.372 & 0.946 & -0.485 & -0.121 & 0.852 \\
& 1.790 & 20.672 & -9.766 & -2.054 & \\
$3-1$ & 0.039 & -0.181 & -0.131 & 1.125 & 0.729 \\
& 0.101 & -2.114 & -1.407 & 10.174 & \\
\hline
\end{tabular}

\begin{tabular}{lrrrrr}
\multicolumn{6}{c}{ Coskewness } \\
\hline \hline Tercile & $\alpha$ & $\beta_{M R P}$ & $\beta_{S M B}$ & $\beta_{H M L}$ & Adj. $R^{2}$ \\
\hline 1 & 0.402 & 0.863 & -0.485 & -0.122 & 0.834 \\
& 1.974 & 19.207 & -9.940 & -2.102 & \\
2 & 0.561 & 1.003 & -0.349 & -0.913 & 0.869 \\
& 1.772 & 14.372 & -4.610 & -10.120 & \\
3 & 0.218 & 1.157 & -0.283 & -1.221 & 0.877 \\
& 0.563 & 13.553 & -3.052 & -11.067 & \\
$3-1$ & -0.184 & 0.294 & 0.202 & -1.099 & 0.744 \\
& -0.453 & 3.272 & 2.072 & -9.467 & \\
\hline
\end{tabular}

\begin{tabular}{lrrrrr}
\multicolumn{6}{c}{ Cokurtosis } \\
\hline \hline Tercile & $\alpha$ & $\beta_{M R P}$ & $\beta_{S M B}$ & $\beta_{H M L}$ & Adj. $R^{2}$ \\
\hline 1 & 0.274 & 1.219 & -0.272 & -1.233 & 0.900 \\
& 0.766 & 15.456 & -3.173 & -12.098 & \\
2 & 0.465 & 0.984 & -0.349 & -0.889 & 0.864 \\
& 1.479 & 14.187 & -4.630 & -9.914 & \\
3 & 0.472 & 0.827 & -0.497 & -0.143 & 0.798 \\
& 2.120 & 16.828 & -9.320 & -2.247 & \\
$3-1$ & 0.198 & -0.393 & -0.225 & 1.091 & 0.799 \\
& 0.533 & -4.789 & -2.529 & 10.290 & \\
\hline
\end{tabular}




\section{Table 7: Descriptive Statistics: Risk Neutral Idiosyncratic Moment Portfolios}

Panels A and B present summary statistics for portfolios sorted on measures of firms' risk-neutral moments. Firms are sorted on average risk-neutral idiosyncratic volatility, skewness, and kurtosis within each calendar quarter into terciles based on $30^{\text {th }}$ and $70^{\text {th }}$ percentiles. Idiosyncratic moments are calculated by regressing daily estimates of each firm's total moment on measures of the risk-neutral co-moment within a calendar quarter:

$$
\begin{gathered}
\mathcal{V}_{i, t}^{Q}=\kappa_{0 i}^{\mathcal{V}}+\kappa_{1 i}^{\mathcal{V}} \operatorname{COV} A R_{i, t}^{Q}+\zeta_{i, t}^{\mathcal{V}} \\
\mathcal{S}_{i, t}^{Q}=\kappa_{0 i}^{\mathcal{S}}+\kappa_{1 i}^{\mathcal{S}} \operatorname{COSKE} W_{i, t}^{Q}+\zeta_{i, t}^{\mathcal{S}} \\
\mathcal{K}_{i, t}^{Q}=\kappa_{0 i}^{\mathcal{K}}+\kappa_{1 i}^{\mathcal{K}} \operatorname{COKU} R T_{i, t}^{Q}+\zeta_{i, t}^{\mathcal{K}}
\end{gathered}
$$

The average unexplained portion of the moments, $\kappa_{0 i}^{\mathcal{V}}, \kappa_{0 i}^{\mathcal{S}}$, and $\kappa_{0 i}^{\mathcal{K}}$, are used as the measure of idiosyncratic moments. We then form equally-weighted portfolios of these firms, holding the moment ranking constant for the subsequent calendar quarter. Risk-neutral moments are calculated using the procedure in Bakshi, Kapadia, and Madan (2003); in Panel A we report results using options closest to three months to maturity, and in Panel B results with options closest to twelve months to maturity. The first column of each panel presents mean monthly returns. The second column presents characteristic-adjusted returns, calculated by determining, for each firm, the Fama-French 5X5 size- and book-to-market portfolio to which it belongs and subtracting that return. The next three columns present the average risk-neutral volatility, skewness and kurtosis of the stocks in the portfolio for the portfolio formation period. The final three columns display the beta, log market value and book-to-market equity ratio of the portfolio. Monthly return data cover the period 4/96 through 12/05, for a total of 117 monthly observations.

Panel A: 3 Months to Maturity

Idiosyncratic Volatility

\begin{tabular}{|c|c|c|c|c|c|c|c|c|}
\hline \multicolumn{9}{|c|}{ Idiosyncratic Kurtosis } \\
\hline Tercile & $\begin{array}{r}\text { Mean } \\
\text { Return }\end{array}$ & $\begin{array}{r}\text { Char-Adj } \\
\text { Return }\end{array}$ & Vol & Skew & Kurt & Beta & $\ln \mathrm{MV}$ & $\mathrm{B} / \mathrm{M}$ \\
\hline 1 & 0.576 & -0.257 & 37.530 & -0.540 & 3.251 & 1.553 & 14.111 & 0.368 \\
\hline 2 & 1.080 & 0.271 & 31.799 & -0.997 & 5.770 & 1.388 & 14.839 & 0.344 \\
\hline 3 & 1.290 & 0.415 & 25.778 & -2.265 & 18.290 & 1.196 & 15.835 & 0.321 \\
\hline $3-1$ & 0.714 & 0.672 & -11.752 & -1.725 & 15.039 & -0.357 & 1.724 & -0.046 \\
\hline $\mathrm{t}(3-1)$ & 1.899 & 2.098 & -27.093 & -28.392 & 14.862 & -11.752 & 42.316 & -6.348 \\
\hline
\end{tabular}

\begin{tabular}{rrrrrrrrr}
\hline \hline & Mean & Char-Adj & & & & & & \\
Tercile & Return & Return & Vol & Skew & Kurt & Beta & $\ln$ MV & B/M \\
\hline 1 & 1.295 & 0.358 & 18.307 & -1.362 & 10.760 & 0.929 & 15.832 & 0.343 \\
2 & 0.990 & 0.106 & 28.727 & -1.226 & 9.756 & 1.375 & 14.754 & 0.337 \\
3 & 0.691 & 0.010 & 49.090 & -1.135 & 5.443 & 1.879 & 14.227 & 0.352 \\
$3-1$ & -0.603 & -0.349 & 30.783 & 0.227 & -5.317 & 0.950 & -1.605 & 0.008 \\
$\mathrm{t}(3-1)$ & -0.751 & -0.542 & 43.943 & 5.258 & -10.422 & 25.650 & -20.252 & 1.091 \\
\hline
\end{tabular}

\begin{tabular}{rrrrrrrrr}
\multicolumn{7}{c}{ Idiosyncratic Skewness } \\
\hline \hline Tercile & Mean & Char-Adj & & & & & & \\
& Return & Return & Vol & Skew & Kurt & Beta & $\ln$ MV & B/M \\
\hline 1 & 1.331 & 0.474 & 31.172 & -2.596 & 14.190 & 1.261 & 15.728 & 0.324 \\
2 & 0.991 & 0.176 & 32.501 & -1.030 & 5.745 & 1.448 & 14.780 & 0.344 \\
3 & 0.658 & -0.190 & 31.179 & -0.166 & 7.394 & 1.403 & 14.306 & 0.365 \\
$3-1$ & -0.673 & -0.664 & 0.008 & 2.430 & -6.796 & 0.142 & -1.422 & 0.041 \\
$\mathrm{t}(3-1)$ & -1.741 & -1.814 & 0.014 & 41.477 & -6.808 & 5.687 & -33.818 & 6.159 \\
\hline
\end{tabular}

Table continued on next page... 
Panel B: 12 Months to Maturity Idiosyncratic Volatility

\begin{tabular}{|c|c|c|c|c|c|c|c|c|}
\hline Tercile & $\begin{array}{r}\text { Mean } \\
\text { Return }\end{array}$ & $\begin{array}{r}\text { Char-Adj } \\
\text { Return }\end{array}$ & Vol & Skew & Kurt & Beta & $\ln \mathrm{MV}$ & $\mathrm{B} / \mathrm{M}$ \\
\hline 1 & 1.282 & 0.348 & 17.692 & -1.336 & 10.811 & 0.901 & 15.941 & 0.342 \\
\hline 2 & 0.963 & 0.102 & 27.984 & -1.146 & 9.212 & 1.378 & 14.755 & 0.335 \\
\hline 3 & 0.740 & 0.019 & 47.234 & -1.186 & 5.998 & 1.910 & 14.115 & 0.357 \\
\hline $3-1$ & -0.542 & -0.329 & 29.542 & 0.150 & -4.813 & 1.009 & -1.826 & 0.015 \\
\hline $\mathrm{t}(3-1)$ & -0.651 & -0.499 & 50.832 & 3.095 & -8.549 & 25.385 & -24.935 & 1.695 \\
\hline \multicolumn{9}{|c|}{ Idiosyncratic Skewness } \\
\hline Tercile & $\begin{array}{r}\text { Mean } \\
\text { Return }\end{array}$ & $\begin{array}{r}\text { Char-Adj } \\
\text { Return }\end{array}$ & Vol & Skew & Kurt & Beta & $\ln \mathrm{MV}$ & $\mathrm{B} / \mathrm{M}$ \\
\hline 1 & 1.359 & 0.466 & 29.761 & -2.618 & 14.620 & 1.284 & 15.672 & 0.326 \\
\hline 2 & 0.962 & 0.203 & 31.108 & -1.019 & 5.803 & 1.427 & 14.829 & 0.339 \\
\hline 3 & 0.668 & -0.215 & 30.988 & -0.077 & 6.770 & 1.409 & 14.296 & 0.369 \\
\hline $3-1$ & -0.692 & -0.681 & 1.227 & 2.540 & -7.850 & 0.125 & -1.376 & 0.043 \\
\hline $\mathrm{t}(3-1)$ & -1.683 & -1.699 & 2.471 & 37.366 & -7.823 & 4.845 & -33.172 & 5.927 \\
\hline \multicolumn{9}{|c|}{ Idiosyncratic Kurtosis } \\
\hline & Mean & Char-Adj & & & & & & \\
\hline Tercile & Return & Return & Vol & Skew & Kurt & Beta & $\ln \mathrm{MV}$ & $\mathrm{B} / \mathrm{M}$ \\
\hline 1 & 0.657 & -0.212 & 36.734 & -0.521 & 3.243 & 1.540 & 14.100 & 0.371 \\
\hline 2 & 1.012 & 0.256 & 30.332 & -0.989 & 5.837 & 1.387 & 14.864 & 0.342 \\
\hline 3 & 1.299 & 0.401 & 25.065 & -2.213 & 18.093 & 1.210 & 15.814 & 0.320 \\
\hline $3-1$ & 0.642 & 0.613 & -11.670 & -1.693 & 14.850 & -0.329 & 1.713 & -0.050 \\
\hline $\mathrm{t}(3-1)$ & 1.683 & 1.721 & -27.075 & -27.646 & 14.589 & -11.455 & 37.402 & -7.007 \\
\hline
\end{tabular}


Table 8: Fama-French Factor Risk Adjustment: Risk Neutral Idiosyncratic Moment-Sorted Portfolios

The table presents the results of time series regressions of excess return differentials (High-Low) between portfolios ranked on idiosyncratic risk neutral volatility, skewness, and kurtosis on the three Fama and French (1993) factors MRP (the return on the value-weighted market portfolio in excess of a one-month T-Bill), SMB (the difference in returns on a portfolio of small capitalization and large capitalization stocks), and HML (the difference in returns on a portfolio of high and low book equity to market equity stocks). Idiosyncratic moments are calculated by regressing daily estimates of each firm's total moment on measures of the risk-neutral co-moment within a calendar quarter:

$$
\begin{gathered}
\mathcal{V}_{i, t}^{Q}=\kappa_{0 i}^{\mathcal{V}}+\kappa_{1 i}^{\mathcal{V}} \operatorname{COV} A R_{i, t}^{Q}+\zeta_{i, t}^{\mathcal{V}} \\
\mathcal{S}_{i, t}^{Q}=\kappa_{0 i}^{\mathcal{S}}+\kappa_{1 i}^{\mathcal{S}} \operatorname{COSKE} W_{i, t}^{Q}+\zeta_{i, t}^{\mathcal{S}} \\
\mathcal{K}_{i, t}^{Q}=\kappa_{0 i}^{\mathcal{K}}+\kappa_{1 i}^{\mathcal{K}} C O K U R T_{i, t}^{Q}+\zeta_{i, t}^{\mathcal{K}}
\end{gathered}
$$

We take the average unexplained portion of the moments, $\kappa_{0 i}^{\mathcal{V}}, \kappa_{0 i}^{\mathcal{S}}$, and $\kappa_{0 i}^{\mathcal{K}}$, and use these as the measure of idiosyncratic moments. Moment-sorted portfolios are equally-weighted, formed on the basis of terciles and reformed each quarter. The table presents point estimates of the coefficients and t-statistics. In Panel A, we use options closest to 3 months to maturity to calculate risk neutral moments; 12 month options are used in Panel B. Data cover the period April 1996 through December 2005 for 117 monthly observations.

3 Months to Maturity

Idiosyncratic Volatility

\begin{tabular}{lrrrrr}
\multicolumn{6}{c}{ Idiosyncratic Volatility } \\
\hline \hline Tercile & $\alpha$ & $\beta_{M R P}$ & $\beta_{S M B}$ & $\beta_{H M L}$ & Adj. $R^{2}$ \\
\hline 1 & 0.576 & 0.788 & -0.487 & -0.238 & 0.835 \\
& 2.895 & 17.962 & -10.236 & -4.197 & \\
2 & 0.524 & 0.956 & -0.400 & -0.842 & 0.872 \\
& 1.817 & 15.043 & -5.803 & -10.257 & \\
3 & 0.092 & 1.295 & -0.212 & -1.199 & 0.873 \\
& 0.216 & 13.881 & -2.089 & -9.944 & \\
$3-1$ & -0.485 & 0.507 & 0.276 & -0.961 & 0.732 \\
& -1.068 & 5.073 & 2.541 & -7.439 & \\
\hline
\end{tabular}

\begin{tabular}{lrrrrr}
\multicolumn{6}{c}{ Idiosyncratic Skewness } \\
\hline \hline Tercile & $\alpha$ & $\beta_{M R P}$ & $\beta_{S M B}$ & $\beta_{H M L}$ & Adj. $R^{2}$ \\
\hline 1 & 0.891 & 0.824 & -0.294 & -0.754 & 0.762 \\
& 2.389 & 10.021 & -3.298 & -7.097 & \\
2 & 0.441 & 1.009 & -0.333 & -0.831 & 0.910 \\
& 1.780 & 18.468 & -5.621 & -11.772 & \\
3 & -0.108 & 1.188 & -0.495 & -0.698 & 0.897 \\
& -0.398 & 19.786 & -7.589 & -8.993 & \\
$3-1$ & -1.000 & 0.364 & -0.200 & 0.056 & 0.146 \\
& -2.569 & 4.244 & -2.151 & 0.509 & \\
\hline
\end{tabular}

\begin{tabular}{lrrrrr}
\multicolumn{6}{c}{ Idiosyncratic Kurtosis } \\
\hline \hline Tercile & $\alpha$ & $\beta_{M R P}$ & $\beta_{S M B}$ & $\beta_{H M L}$ & Adj. $R^{2}$ \\
\hline 1 & -0.285 & 1.272 & -0.394 & -0.729 & 0.897 \\
& -0.960 & 19.438 & -5.550 & -8.617 & \\
2 & 0.571 & 0.973 & -0.367 & -0.823 & 0.897 \\
& 2.213 & 17.107 & -5.946 & -11.194 & \\
3 & 0.892 & 0.788 & -0.351 & -0.736 & 0.809 \\
& 2.895 & 11.607 & -4.758 & -8.387 & \\
$3-1$ & 1.177 & -0.484 & 0.044 & -0.007 & 0.377 \\
& 3.638 & -6.793 & 0.565 & -0.075 & \\
\hline \hline
\end{tabular}

Table continued on next page. 
12 Months to Maturity

Idiosyncratic Volatility

\begin{tabular}{lrrrrr}
\hline \hline Tercile & $\alpha$ & $\beta_{M R P}$ & $\beta_{S M B}$ & $\beta_{H M L}$ & Adj. $R^{2}$ \\
\hline 1 & 0.595 & 0.743 & -0.469 & -0.230 & 0.818 \\
& 2.971 & 16.838 & -9.792 & -4.027 & \\
2 & 0.489 & 0.981 & -0.415 & -0.857 & 0.883 \\
& 1.741 & 15.857 & -6.176 & -10.727 & \\
3 & 0.120 & 1.307 & -0.211 & -1.188 & 0.857 \\
& 0.264 & 13.067 & -1.945 & -9.188 & \\
$3-1$ & -0.475 & 0.565 & 0.258 & -0.958 & 0.717 \\
& -0.983 & 5.304 & 2.228 & -6.965 & \\
\hline
\end{tabular}

\begin{tabular}{lrrrrr}
\multicolumn{6}{c}{ Idiosyncratic Skewness } \\
\hline \hline Tercile & $\alpha$ & $\beta_{M R P}$ & $\beta_{S M B}$ & $\beta_{H M L}$ & Adj. $R^{2}$ \\
\hline 1 & 0.905 & 0.827 & -0.261 & -0.755 & 0.758 \\
& 2.369 & 9.822 & -2.855 & -6.932 & \\
2 & 0.406 & 1.023 & -0.334 & -0.840 & 0.900 \\
& 1.522 & 17.399 & -5.238 & -11.058 & \\
3 & -0.075 & 1.166 & -0.527 & -0.686 & 0.897 \\
& -0.284 & 19.938 & -8.293 & -9.071 & \\
$3-1$ & -0.981 & 0.339 & -0.265 & 0.069 & 0.121 \\
& -2.334 & 3.657 & -2.640 & 0.577 & \\
\hline
\end{tabular}

\begin{tabular}{lrrrrr}
\multicolumn{6}{c}{ Idiosyncratic Kurtosis } \\
\hline \hline Tercile & $\alpha$ & $\beta_{M R P}$ & $\beta_{S M B}$ & $\beta_{H M L}$ & Adj. $R^{2}$ \\
\hline 1 & -0.217 & 1.276 & -0.430 & -0.699 & 0.897 \\
& -0.744 & 19.815 & -6.145 & -8.403 & \\
2 & 0.517 & 0.977 & -0.374 & -0.844 & 0.895 \\
& 1.968 & 16.858 & -5.941 & -11.263 & \\
3 & 0.896 & 0.779 & -0.307 & -0.738 & 0.790 \\
& 2.732 & 10.771 & -3.908 & -7.900 & \\
$3-1$ & 1.114 & -0.497 & 0.123 & -0.039 & 0.330 \\
& 3.272 & -6.629 & 1.509 & -0.400 & \\
\hline
\end{tabular}




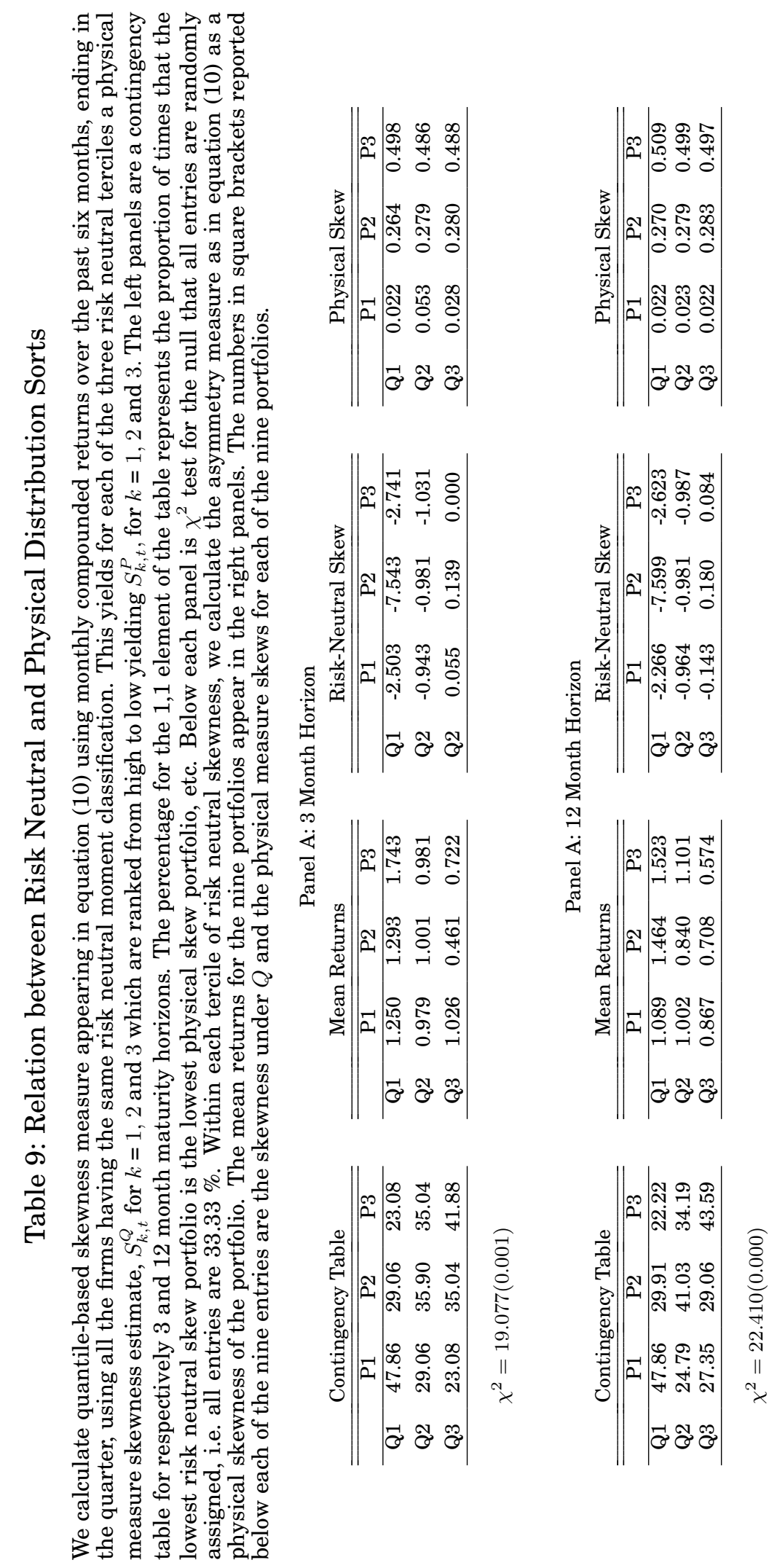




\section{Table 10: Relation of Valuation Ratios to Risk Neutral Moments}

We sort securities into decile portfolios based on risk neutral moment estimates, and then compute portfolio statistics. The statistics are the mean log market value, book-to-market ratio, beta, and risk neutral moments of the portfolio. In addition, we calculate earnings to price (E/P) ratios for different measures of earnings. The $\mathrm{E} / \mathrm{P}$ ratios are $\mathrm{FY} 0$, the $\mathrm{E} / \mathrm{P}$ ratios based on closest monthly historical earnings per share figures (constructed as in Fama and French (1993)), FY1, the E/P ratio based on I/B/E/S consensus mean estimates of next fiscal-yearend's earnings per share, and FY2, the E/P ratio calculated based on I/B/E/S consensus mean earnings per share estimates for the fiscal year ending two years after the most recent fiscal year end.

Panel A: Volatility

\begin{tabular}{lrrrrrrrrr}
\hline \hline Decile & MV & BM & Beta & Vol & Skew & Kurt & FY0 & FY1 & FY2 \\
\hline 1 & 16.088 & 0.350 & 0.817 & 0.141 & -1.334 & 14.095 & 5.228 & 3.454 & 3.952 \\
2 & 15.755 & 0.344 & 0.882 & 0.181 & -1.253 & 8.924 & 4.656 & 3.510 & 4.124 \\
3 & 15.385 & 0.354 & 1.050 & 0.212 & -1.264 & 9.345 & 4.035 & 3.363 & 4.105 \\
4 & 15.161 & 0.325 & 1.157 & 0.241 & -1.372 & 9.202 & 4.069 & 3.116 & 3.937 \\
5 & 14.701 & 0.347 & 1.288 & 0.268 & -1.059 & 9.982 & 3.568 & 2.987 & 3.862 \\
6 & 14.563 & 0.359 & 1.413 & 0.298 & -1.101 & 11.891 & 2.858 & 2.442 & 3.561 \\
7 & 14.377 & 0.338 & 1.568 & 0.333 & -1.073 & 6.952 & -0.094 & 1.951 & 3.140 \\
8 & 14.086 & 0.362 & 1.710 & 0.380 & -1.063 & 6.146 & 0.450 & 1.151 & 2.790 \\
9 & 14.107 & 0.355 & 1.866 & 0.459 & -1.146 & 5.498 & -1.050 & 0.993 & 2.843 \\
10 & 14.152 & 0.393 & 2.043 & 0.658 & -1.611 & 7.706 & -5.637 & -1.263 & 1.455 \\
\hline
\end{tabular}

Panel B: Skewness

\begin{tabular}{lrrrrrrrrr}
\hline \hline Decile & MV & BM & Beta & Vol & Skew & Kurt & FY0 & FY1 & FY2 \\
\hline 1 & 16.181 & 0.316 & 1.078 & 0.289 & -4.279 & 26.083 & 3.757 & 3.116 & 3.816 \\
2 & 15.546 & 0.344 & 1.266 & 0.322 & -2.404 & 11.800 & 2.739 & 2.613 & 3.588 \\
3 & 15.194 & 0.332 & 1.389 & 0.334 & -1.793 & 8.669 & 2.757 & 2.004 & 3.042 \\
4 & 14.918 & 0.367 & 1.449 & 0.334 & -1.385 & 6.927 & 2.104 & 2.503 & 3.708 \\
5 & 14.779 & 0.356 & 1.431 & 0.324 & -1.094 & 5.657 & 1.502 & 2.029 & 3.334 \\
6 & 14.692 & 0.333 & 1.416 & 0.320 & -0.838 & 4.771 & 1.167 & 2.130 & 3.256 \\
7 & 14.582 & 0.372 & 1.387 & 0.312 & -0.608 & 4.227 & 0.643 & 1.475 & 2.833 \\
8 & 14.326 & 0.357 & 1.405 & 0.310 & -0.366 & 3.724 & 0.495 & 1.836 & 3.420 \\
9 & 14.092 & 0.356 & 1.394 & 0.311 & -0.100 & 3.411 & 0.901 & 1.632 & 3.261 \\
10 & 14.092 & 0.398 & 1.425 & 0.313 & 0.556 & 15.066 & 2.170 & 2.012 & 3.449 \\
\hline
\end{tabular}

Panel C: Kurtosis

\begin{tabular}{lrrrrrrrrr}
\hline \hline Decile & MV & BM & Beta & Vol & Skew & Kurt & FY0 & FY1 & FY2 \\
\hline 1 & 13.714 & 0.432 & 1.485 & 0.393 & -0.182 & 1.571 & -2.353 & 0.567 & 2.586 \\
2 & 14.046 & 0.376 & 1.574 & 0.367 & -0.370 & 2.402 & -0.883 & 0.670 & 2.619 \\
3 & 14.212 & 0.359 & 1.508 & 0.358 & -0.552 & 3.120 & 1.174 & 1.204 & 2.666 \\
4 & 14.509 & 0.364 & 1.394 & 0.331 & -0.693 & 3.862 & 2.455 & 2.211 & 3.525 \\
5 & 14.684 & 0.369 & 1.417 & 0.327 & -0.839 & 4.722 & 2.269 & 2.535 & 3.664 \\
6 & 14.846 & 0.344 & 1.360 & 0.309 & -0.976 & 5.827 & 2.827 & 2.443 & 3.562 \\
7 & 15.042 & 0.326 & 1.366 & 0.301 & -1.311 & 7.371 & 2.130 & 2.814 & 3.837 \\
8 & 15.352 & 0.341 & 1.249 & 0.279 & -1.592 & 9.485 & 3.307 & 2.805 & 3.842 \\
9 & 15.662 & 0.308 & 1.187 & 0.262 & -2.140 & 13.111 & 3.450 & 2.819 & 3.662 \\
10 & 16.293 & 0.316 & 1.094 & 0.242 & -3.636 & 38.691 & 3.528 & 3.107 & 3.785 \\
\hline
\end{tabular}




\section{Technical Appendices}

\section{A1 Estimation of Risk Neutral Moments - Details}

To estimate the higher moments of the (risk-neutral) density function of individual securities, we use the results in Bakshi and Madan (2000) and Bakshi, Kapadia, and Madan (2003). Bakshi and Madan (2000) show that any payoff to a security can be constructed and priced using a set of option prices with different strike prices on that security. The assumptions used in Bakshi and Madan (2000) are standard for the no-arbitrage option pricing literature, and can cover various configurations of primitive uncertainty, ranging from discrete time dynamics, continuous-time diffusion, pure-jump, to jump diffusion environments. Bakshi, Kapadia, and Madan (2003), assuming constant instantaneous interest rates, demonstrate how to express the risk-neutral density moments in terms of quadratic, cubic, and quartic payoffs. In particular, Bakshi, Kapadia, and Madan (2003) show that one can express the $\tau$-maturity price of a security that pays the quadratic, cubic, and quartic return on the base security $i$ as

$$
\begin{aligned}
V_{i, t}(\tau)= & \int_{S_{i, t}}^{\infty} \frac{2\left(1-\ln \left(K_{i} / S_{i, t}\right)\right)}{K_{i}^{2}} C_{i, t}\left(\tau ; K_{i}\right) d K_{i} \\
& +\int_{0}^{S_{i, t}} \frac{2\left(1+\ln \left(K_{i} / S_{i, t}\right)\right)}{K_{i}^{2}} P_{i, t}\left(\tau ; K_{i}\right) d K_{i} \\
W_{i, t}(\tau)= & \int_{S_{i, t}}^{\infty} \frac{6\left(\ln \left(K_{i} / S_{i, t}\right)\right)-3\left(\ln \left(K_{i} / S_{i, t}\right)\right)^{2}}{K_{i}^{2}} C_{i, t}\left(\tau ; K_{i}\right) d K_{i} \\
& +\int_{0}^{S_{i, t}} \frac{6\left(\ln \left(K_{i} / S_{i, t}\right)\right)+3\left(\ln \left(K_{i} / S_{i, t}\right)\right)^{2}}{K_{i}^{2}} P_{i, t}\left(\tau ; K_{i}\right) d K_{i} \\
X_{i, t}(\tau)= & \int_{S_{i, t}}^{\infty} \frac{12\left(\ln \left(K_{i} / S_{i, t}\right)\right)^{2}-4\left(\ln \left(K_{i} / S_{i, t}\right)^{3}\right)}{K_{i}^{2}} C_{i, t}\left(\tau ; K_{i}\right) d K_{i} \\
& +\int_{0}^{S_{i, t}} \frac{12\left(\ln \left(K_{i} / S_{i, t}\right)\right)^{2}+4\left(\ln \left(K_{i} / S_{i, t}\right)^{3}\right)}{K_{i}^{2}} P_{i, t}\left(\tau ; K_{i}\right) d K_{i}
\end{aligned}
$$

where $V_{i, t}(\tau), W_{i, t}(\tau)$, and $X_{i, t}(\tau)$ are the time $t$ prices of $\tau$-maturity quadratic, cubic, and quartic contracts, respectively. $C_{i, t}(\tau ; K)$ and $P_{i, t}(\tau ; K)$ are the time $t$ prices of European calls and puts written on the underlying stock with strike price $K$ and expiration $\tau$ periods from time $t$. As equations (A1), (A2) and (A3) show, the procedure involves using a weighted sum of (out-of-the-money) options across varying strike prices to construct the prices of payoffs related to the second, third and fourth moments of returns. 


\section{A2 Option Data Filters}

We do not adjust for early exercise premia in our option prices. As Bakshi, Kapadia, and Madan (2003) note, the magnitude of such premia in OTM calls and puts is very small, and the implicit weight that options receive in our estimation of higher moments declines as they get closer to at-the-money. Using the same method, BKM show in their empirical work that, for their sample of OTM options, the implied volatilities from the Black-Scholes model and a model of American option prices have negligible differences.

In estimating equations (A1) - (A3), we use equal numbers of out-of-the-money (OTM) calls and puts for each stock for each day. Thus, if there are $n$ OTM puts with closing prices available on day $t$ we require $n$ OTM call prices. If there are $N>n$ OTM call prices available on day $t$, we use the $n$ OTM calls which have the most similar distance from stock to strike as the OTM puts for which we have data. We require a minimum $n$ of 2 . Dennis and Mayhew (2009) examine and estimate the magnitude of the bias induced in Bakshi-Kapadia-Madan estimates of skewness which is due to discreteness in strike prices. For $\$ 5(\$ 2.50)$ differences in strike prices, they estimate the bias in skewness is approximately -0.07 (0.05). Since most stocks have the same differences across strike prices, however, the relative bias should be approximately the same across securities, and should not affect either the ranking of securities into portfolios based on skewness, or the nature of the cross-sectional relation between skewness and returns which we examine. In our empirical implementation, the moneyness of the options in our sample ranged roughly from .8 to 1.2 with on average 5 equally spaced contracts. We eliminate options in which there is no trading volume in any option of the same maturity. We also eliminate options with prices less than $\$ 0.50$ in order to remove especially thinly traded options. In unreported results, we examine the sensitivity of our results to changing the requirement of options available and both increasing and decreasing the price filter. The results are qualitatively unchanged and are discussed in BLANK (2011). The resulting set of data consists of 3,722,700 daily observations across firms and maturities over the 1996-2005 sample period. 